\title{
LA PROSPERITAT. NOU BARRIS (Barcelona) CONSTRUCCIÓN DEL ESPACIO PÚBLICO PARA TODOS
}

\author{
Nicolás del Real \\ Sociólogo.nicolas.delrealf@gmail.com
}

Recibido: 29/04/2020 Evaluado: 11/05/2020 Publicado: 01/06/2020

\section{RESUMEN}

El presente trabajo tiene por objetivo realizar una primera aproximación al barrio La Prosperitat (Nou Barris) bajo el contexto del confinamiento en tiempos de COVID19, el cual nos obliga a reconsiderar los procesos de trabajo y mecanismos de aproximación a un territorio intocable.

La herramienta Google Earth y las distintas plataformas que nos proporcionan información virtual de la ciudad, darán cuenta de nuestras posibilidades y limitaciones para acceder a un barrio que solo podremos visitar desde la pantalla.

Analizaremos La Prosperitat abordando sus límites y contexto territorial, su evolución en el tiempo, sus principales características socio económicas, su relación con políticas y programas urbanos, su conectividad y espacio público, destacando las principales intervenciones realizadas en él.

PALABRAS CLAVE: Espacio Público; Diseño Urbano; Barrio; La Prosperitat; Nou Barris; COVID19; Confinamiento.

\section{ABSTRACT}

The objective of this investigation is to make a first approach to the La Prosperitat neighbourhood (Nou Barris) in the context of the confinement in the time of COVID19, which forces us to reconsider the work processes and approach mechanisms in an untouchable territory.

Using the Google Earth tool and diverse platforms will provide us with virtual information about the city, out accessing possibilities and limitations in a neighbourhood that can only be visited from the screen.

The analysis from La Prosperitat presents its territorial and context limitations, its evolution over time, its main socio-economic characteristics, its relationship with urban policies and programs, its connectivity and public space highlighting the main interventions carried out in it.

KEYWORDS: Public Space; Urban Design; Neighborhood; La Prosperitat; Nou Barris; COVID19; Lockdown. 
condiciones normales, serían prescindibles. Hoy por hoy contamos con plataformas digitales que disponen de inagotable información.

Barcelona es una ciudad que, por sobre muchas otras, se ha tomado en serio la importancia de recopilar, organizar y disponer (de manera pública) una batería contundente de datos y documentación que permite y propicia la producción constante de investigación, análisis y observación de su territorio. Plataformas como el Instituto Cartográfico y Geológico de Catalunya (ICGC); El Registro de Planeamiento Urbanístico (RPUC); Portal de Información Urbanística (PIU); Catálogo de Arte Público; Nomenclator; el Departamento de Estadísticas y Difusión de Datos; el Archivo Histórico, entre otras fuentes institucionales y "en línea" que nos proporcionan información "a distancia". Por otro lado, la herramienta Google Earth y la aplicación Street View nos permiten sobrevolar y transitar virtualmente el territorio, propiciando una aproximación ex situ pero bastante cercana dentro de sus posibilidades limitadas. Ya a escala local, la información disponible a nivel "barrio", dependerá de distintos factores asociados, destacando elementos como cohesión e identidad por parte de las comunidades. En barrios con comunidades más activas, cohesionadas y con un sentido de pertenencia más desarrollado, es probable que encontremos una mayor producción y rescate de documentación vinculada a la memoria colectiva del territorio.

En el caso de La Prosperitat, barrio fuertemente identificado con su alto grado de cohesión y asociatividad, hecho potenciado por el reciente cumplimiento de su centenario (1919-2019), nos encontramos con una interesante cantidad de documentación disponible (dejando de lado el ámbito fotográfico, careciendo de material digitalizado).

Como vemos, el problema no será cuantitativo (cantidad de información disponible) sino que cualitativo (calidad y fiabilidad). El territorio es el principal mecanismo para el contraste y constatación de la información. Por lo mismo, no poder acceder a éste siempre será un bache irrevocable. Consientes de esto buscaremos aproximarnos lo más posible. Acercarnos a una meta que sabemos inalcanzable, pero que, cada ves más, podemos, al menos, reconocer.

Analizaremos el barrio La Prosperitat abordando sus límites y contexto territorial, su evolución en el tiempo (urbana y social), sus principales características socio económicas, contrastando con los barrios colindantes, su relación (o falta de ella) con políticas y programas urbanos, su conectividad (accesos y medios de transporte) y su Espacio Público (Plano horizontal, vertical, del aire y cenital), destacando las principales intervenciones realizadas en el barrio. 


\section{LÍMITES DELTERRITORIO}

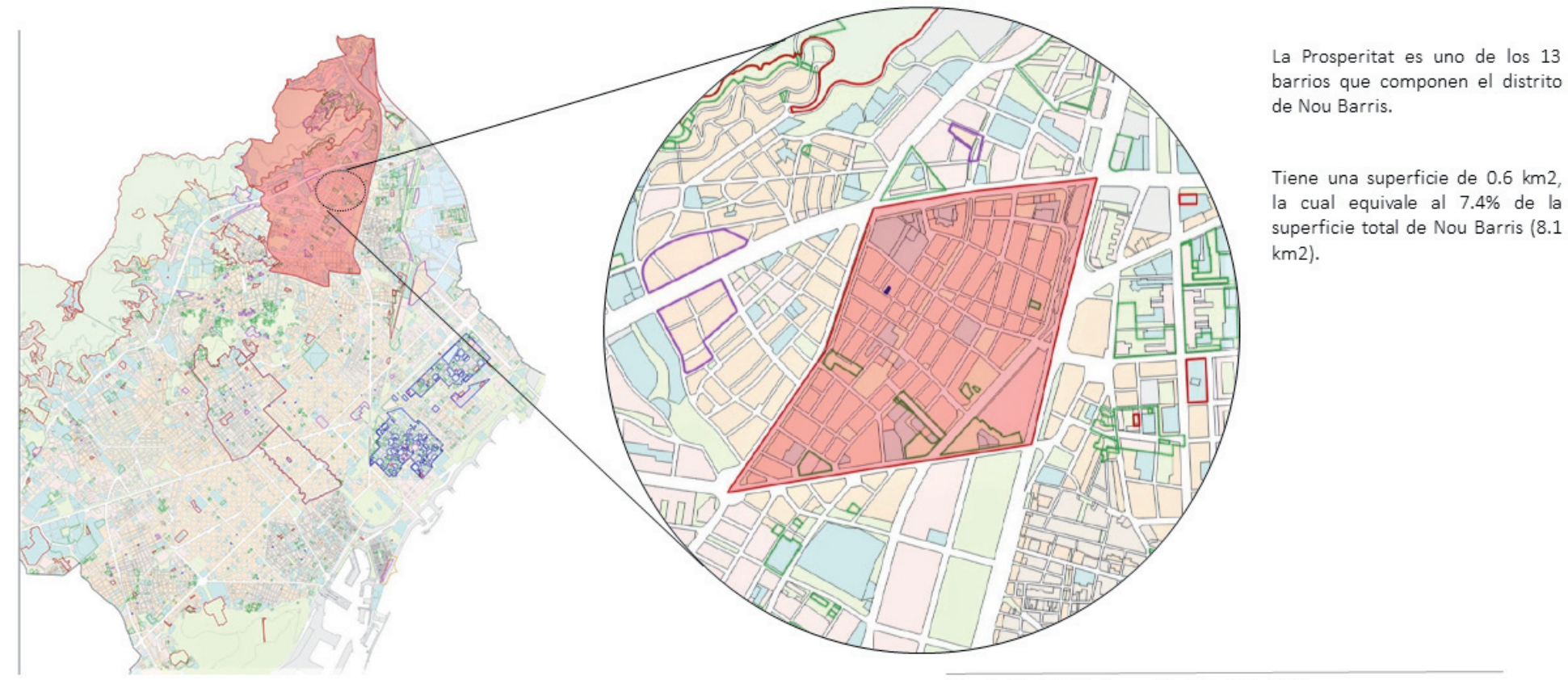

Fuente: Portal de Información Urbanística BCN

httos://aiuntament barcelona cat/informaciourbanistica/cerca/es/tematic/5/

\section{LÍMITES DEL TERRITORIO}

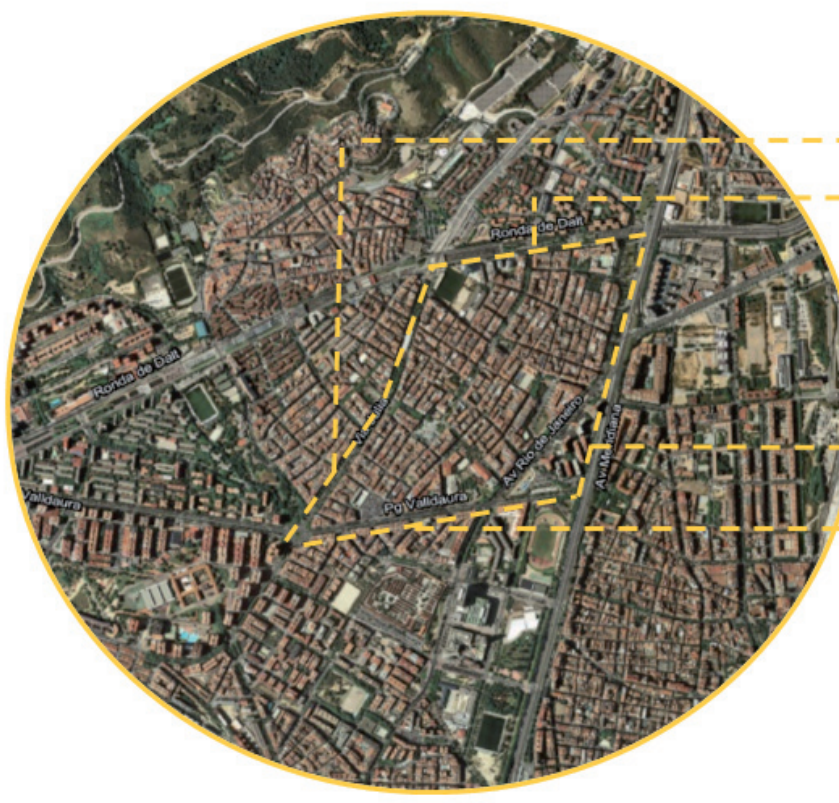

Límite noroeste, Vía Júlia, frontera con el barrio

de Verdúm

Límite noreste, Via Favència, frontera con el barrio de

Trinitat Nova

Límite sureste, Avinguda Meridiana, frontera con el

distrito de Sant Andreu del Palomar

Limite oeste, Passeig Valldaura, frontera con

el barrio de Porta

Fuente: Ortofoto ICC, Portal de Información Urbanística BCN

https://ajuntament.barcelona.cat/informaciourbanistica/cerca/es/tematic/5/ 


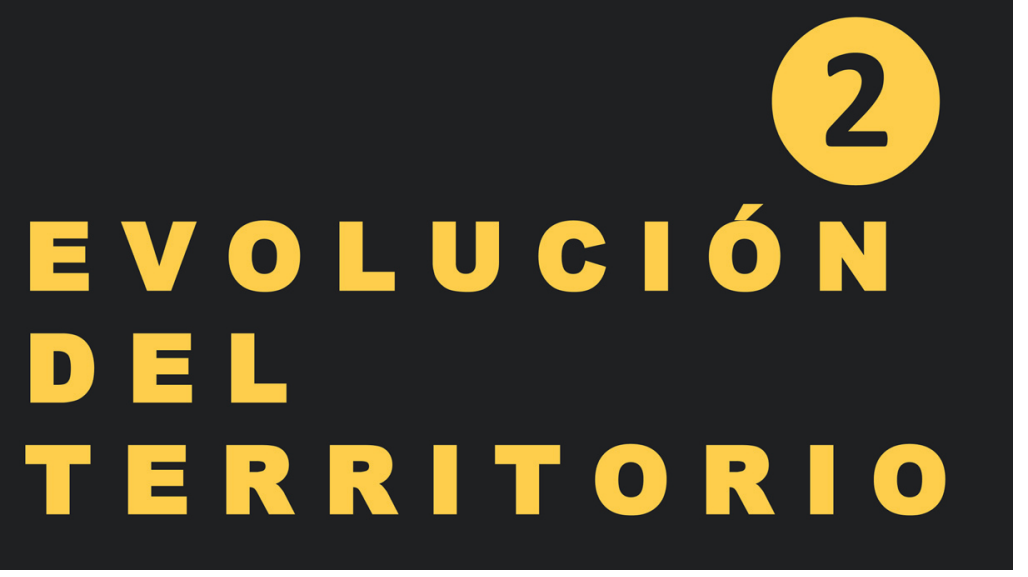

\section{LINEA DEL TIEMPO}

Presentaremos el transitar del barrio de La Prosperitat, desde su pasado agrícola hasta su consolidación urbana e identitaria. La propuesta considera una apuesta por comprender dicha evolución desde 4 líneas, cada una enfatizando aspectos distintos, aunque siempre en relación con la historia del barrio.

La idea es comprender que no existe "una" línea de tiempo, sino acontecimientos significativos que, aunque entrelazados, pueden distinguirse. Si bien esta propuesta puede ser un tanto confusa, nos permite dar cuenta de "momentos" en la evolución del territorio en que ciertos ámbitos tienen mayor preponderancia. La categorías son las siguientes:

HSB Hitos sociales y culturales directamente asociados al barrio en la conformación de su identidad

HUB Hitos urbanos del barrio directamente asociados a la conformación física del territorio

HUC Hitos urbanos de la ciudad que tendrán repercusión en la conformación del barrio

HSC Hitos sociales y culturales de la ciudad/país, que tendrán repercusión en la conformación social del barrio

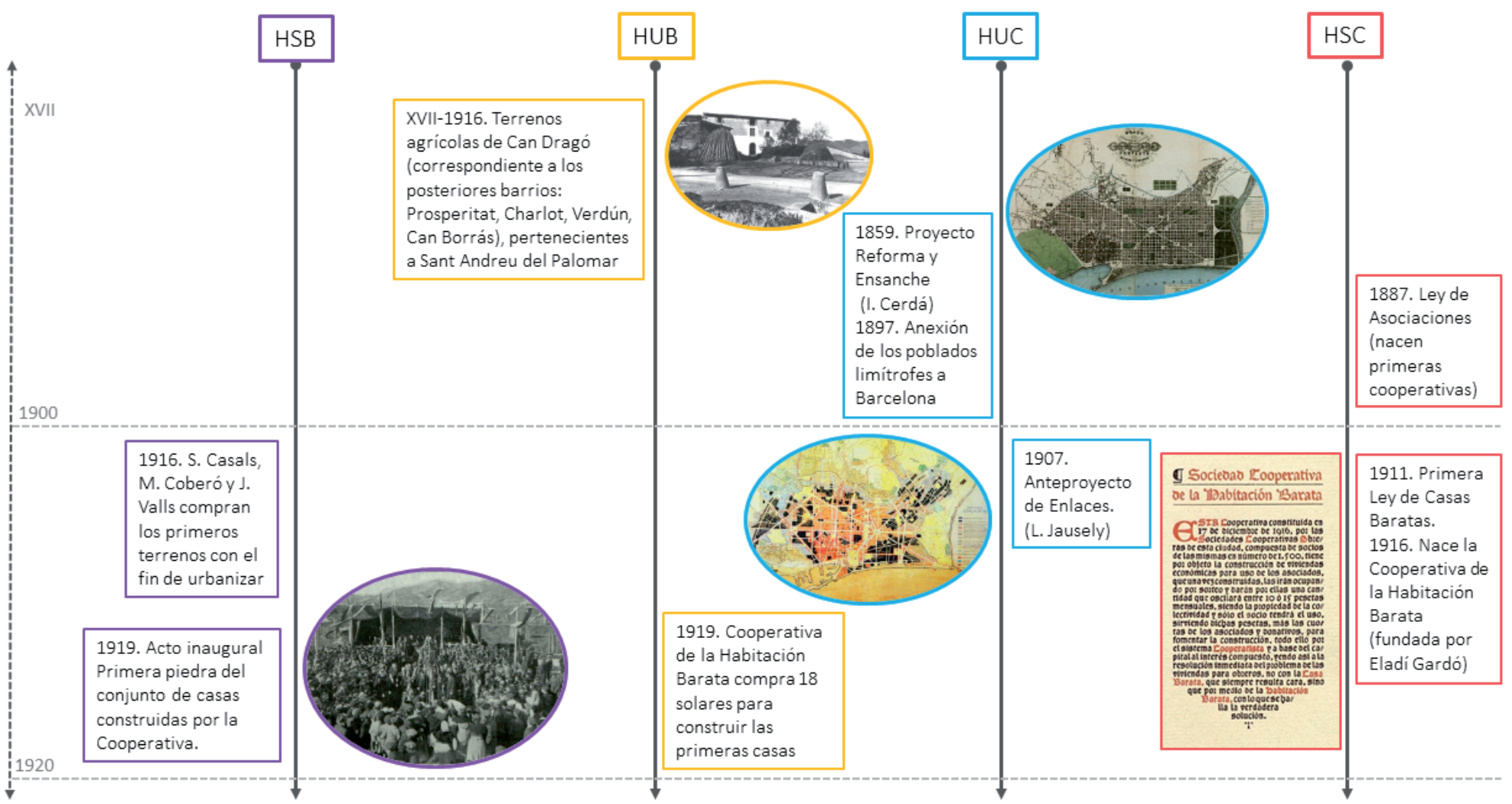



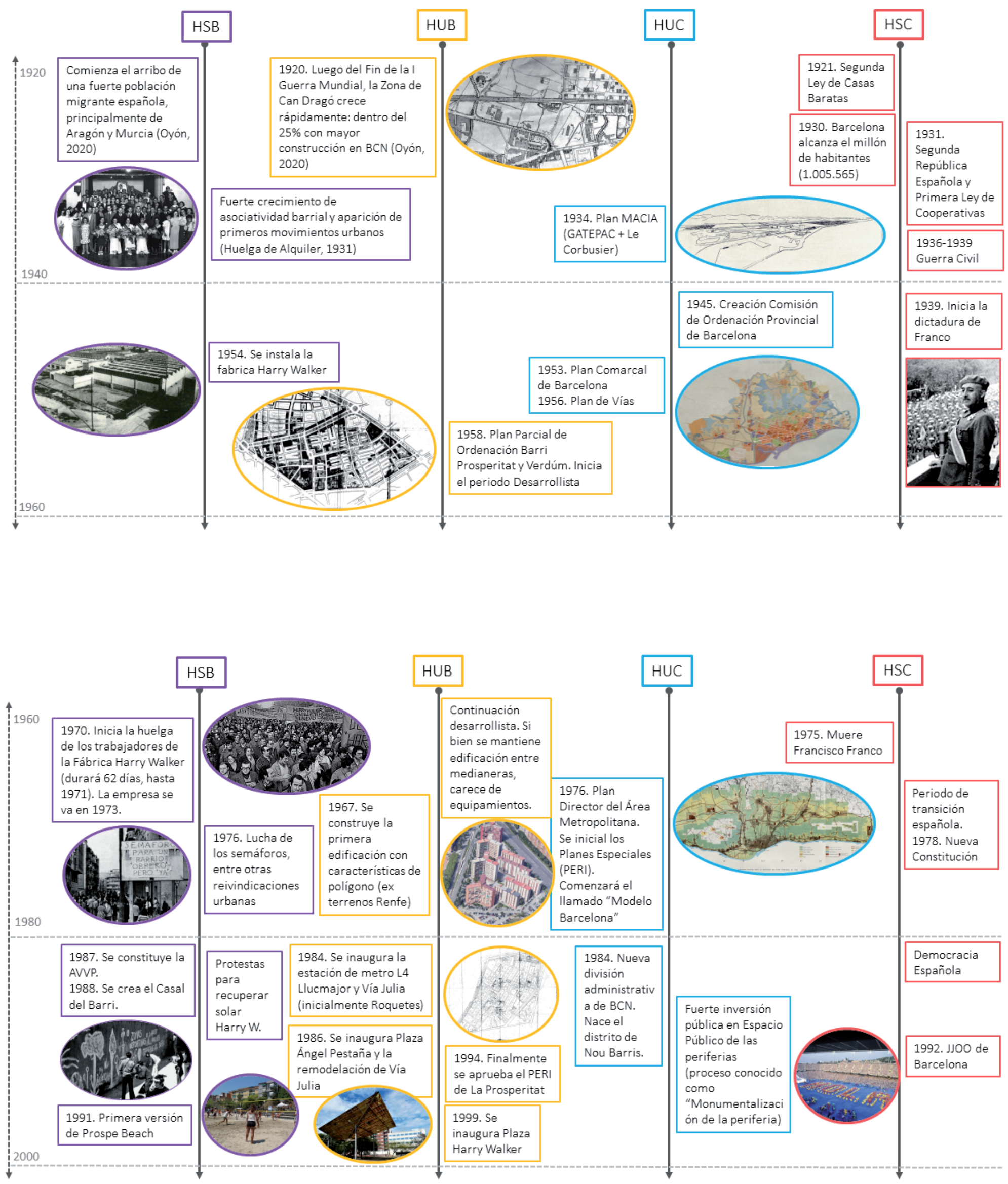


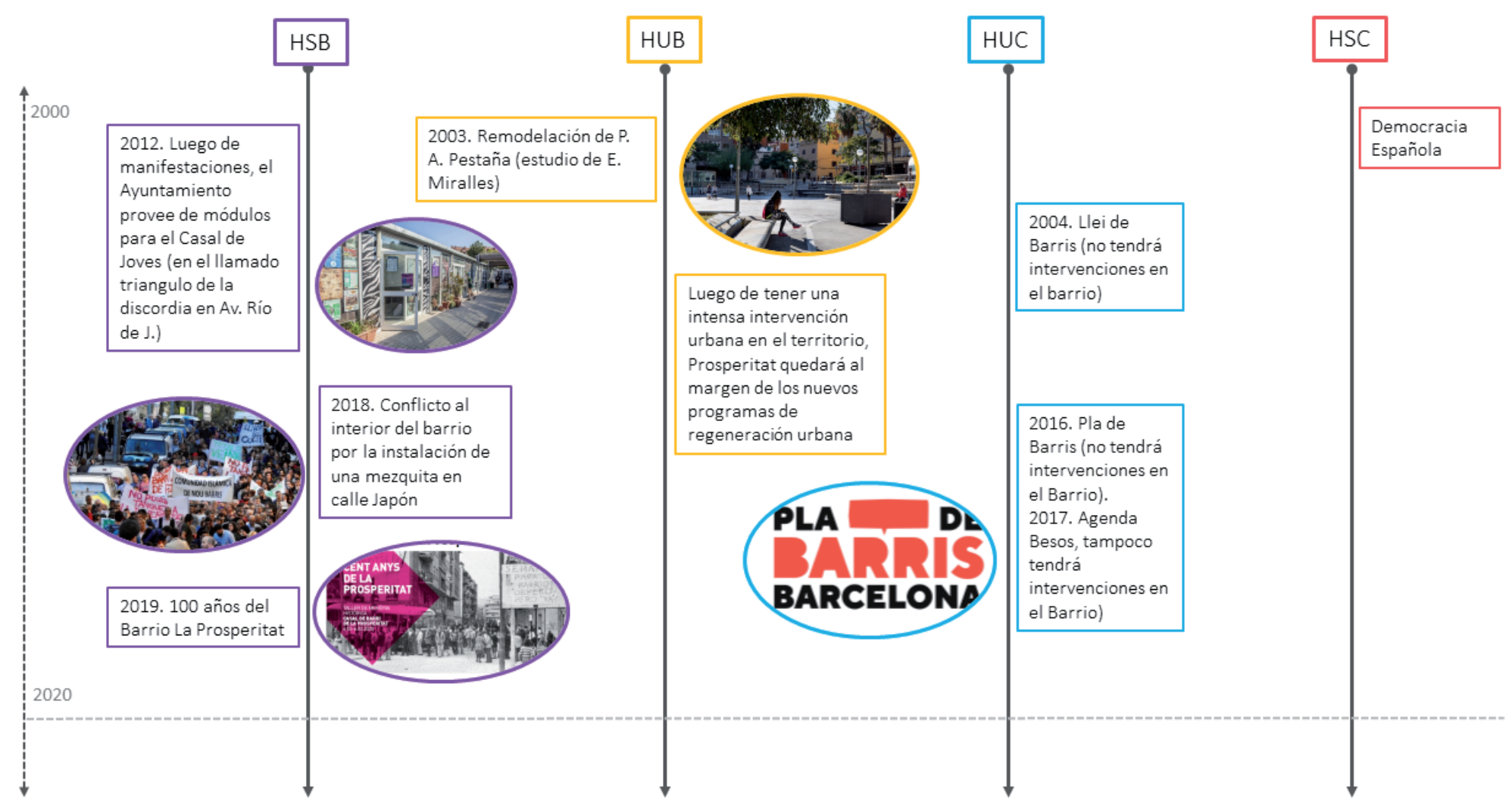

\section{TERRITORIO EN EL TIEMPO}

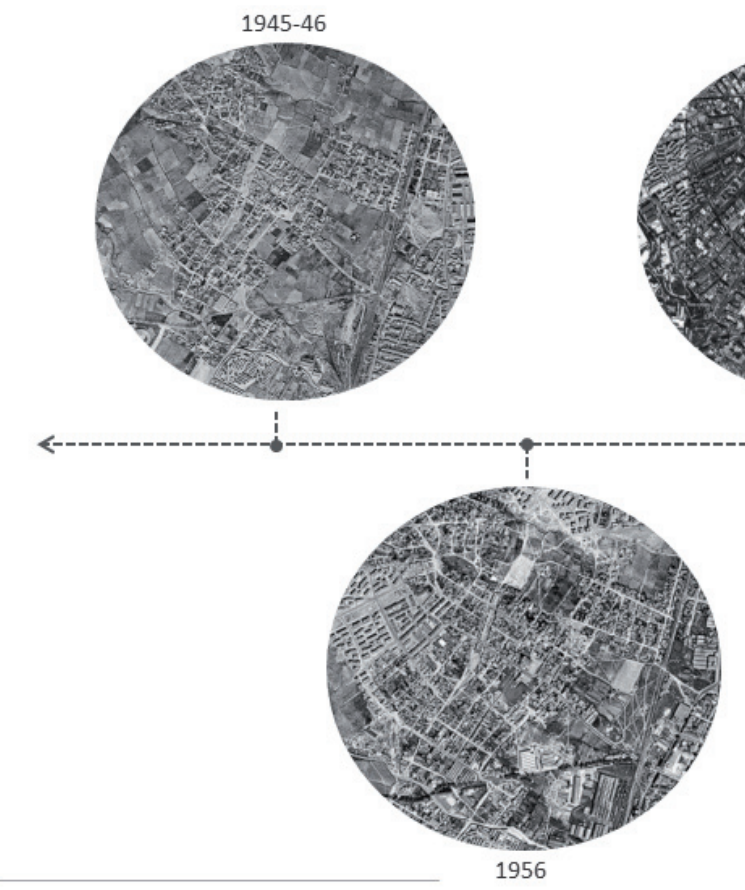

1986

Fuente: Visualizador de Cambios Urbanísticos

https://betaportal.icgc.cat/canurb/ 


\section{TERRITORIO EN EL TIEMPO}

Imagen de la celebración de la primera piedra del conjunto de la Cooperativa de Habitación Barata, junto con la aprobación de los planos de una casa construida por Joaquim Valls, uno de los primeros propietarios (ambas de 1919).
Primera piedra. Fuente: Revista La Hormiga de Oro, 11 de gener de 1919

https://laprosperitat100anys.files.wordpres s.com

Planos: Arxiu Municipal de Barcelona http://w151.bcn.cat/opac/
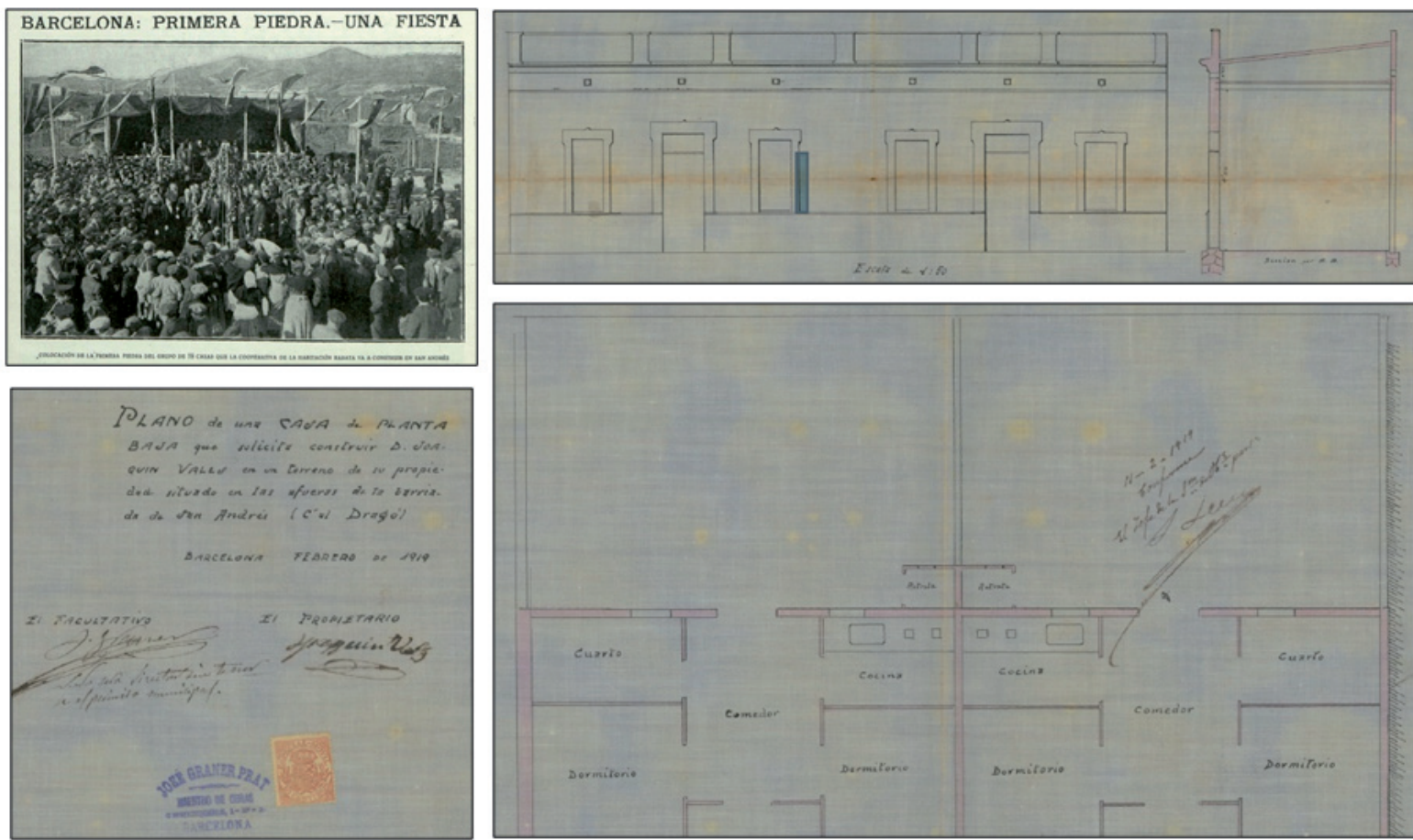

\section{TERRITORIO EN EL TIEMPO}

Podemos ver uno de los primeros planos que

muestran el desarrollo inicial del barrio (1924).

Sabemos que desde su origen, la proximidad de las casas, la poca anchura de las calles, fueron factores que mantuvieron una escala que determinaría el entorno socio-físico del territorio.

Esta proximidad urbana, propiciaría un habitar "a pie" del territorio, fomentando una presencia social que luego puede determinar ciertos grados de cohesión en el barrio (Mayol,1999).

Fragmento plano Sant Andreu, 1924

Fuente: AMDSA

Primer conjunto de casa en La Prosperitat

En: https://www.prosperitat.org/category/memoriahistorica-i-patrimoni/

Can Dragó, masía ubicada en lo que después serian terrenos de Renfe, actual triangulo entre Meridiana y Av Rio de Janeiro. 


\section{TERRITORIO EN EL TIEMPO}

P. MACIA (1934)

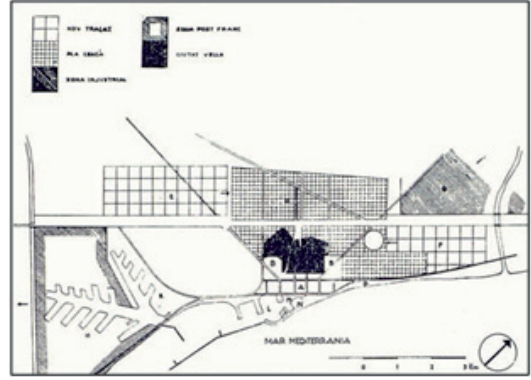

El periodo de mayor transformación del territorio de barrio, será la segunda mitad del s. XX.

El Plan Parcial para Verdúm y Prosperitat, derivado del P. Comarcal, iniciarian un periodo masivo de edificación en el barrio. En efecto, la mayoría de las construcciones serán entre los años 60 y finales del 70. Sin embargo, la edificación de vivienda dejaría de lado al espacio ý equipamiento público, lo cual intentaría remediar el posterior Plan Especial.
P. COMARCAL (1953)
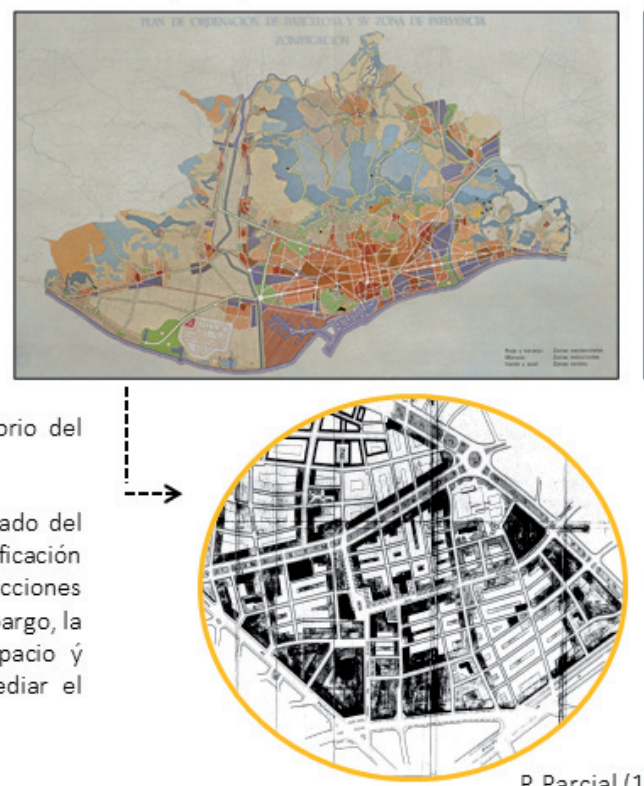

P. Parcial (1958
P. Director del Área Metropolitana (1976)
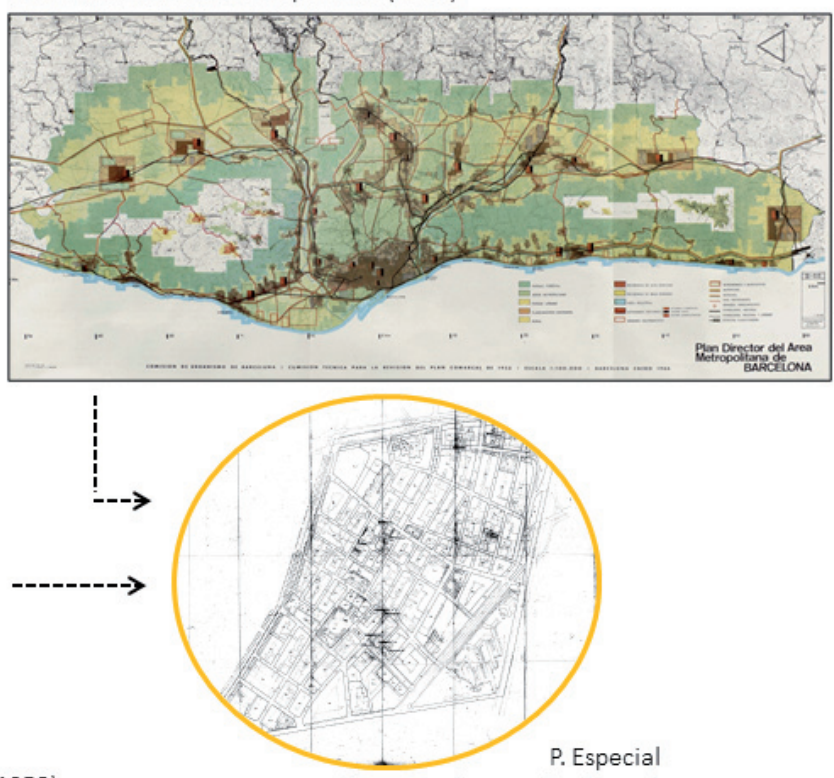

(apr. inicial 1988 - final 1994)

Fuente P. MACIA:Tarragó, S. GATEPAC I, EI Pla Macia o La Nova Barcelona. Cuadernos de Arquitecturay Urbansmo, $\mathrm{N}^{\circ} 90(1972)$

Fuente P. Comarcal y P. Director Área Metropolitana: ElÁrea Metropolitana de Barcelona. Cuadernos de Arquitectura y Urbansmo, $\mathrm{N}^{\circ} 87$ (1972).

Fuente planos P. Parcial y P. Especial: Registro de Planeamiento Urbanístico de Catalunya.

En: http://ptop.gencat.cat/rpucportal/AppJava/cercaExpedient.do

\section{TERRITORIO EN EL TIEMPO}

Si revisamos las toponimias de las calles del barrio, podemos ver que existe una prevalencia de nombres vinculados a personajes y lugares de los orígenes de la zona.

Una importante cantidad de calles asociadas a propietarios (incluso a parejas de los mismos), sumado a espacios naturales y construidos.

Más allá de las calles, también habría que contabilizar el nombre de ciertos espacios públicos como la Plaza Angel Pestaña (anarcosindicalista español, dirigente de la CNT, con mucha presencia en la zona) y la Plaza de las trabajadoras y trabajadores de la Harry Walker (en honor a la histórica huelga. Junto con la calle Pablo Iglesias (fundador del PSOE), dan cuenta del carácter reivindicativo del barrio.

\begin{tabular}{|c|c|}
\hline CATEGORÍA & NOMBRE DE LACAШE \\
\hline \multirow{9}{*}{$\begin{array}{l}\text { Vinculadas con } \\
\text { propietariosy } \\
\text { personajes del } \\
\text { Barrio }\end{array}$} & Argullós, carrerd' \\
\hline & Joaquim Valls, carrer de \\
\hline & Boada, carrer de \\
\hline & Badosa, carrer de \\
\hline & Enric Casanovas, carrer d' \\
\hline & Borràs, carrer de \\
\hline & Santa Engràcia, carrer de \\
\hline & Mas Duran, carrer del \\
\hline & Borges Blanques, carrer de les \\
\hline \multirow{12}{*}{$\begin{array}{l}\text { Vinculadas con } \\
\text { lugares, paisajes, } \\
\text { construcciones o } \\
\text { hitos de la zona }\end{array}$} & Tissó, carrer d'en \\
\hline & Vinyar, carrer del \\
\hline & Conveni, carrer del \\
\hline & Flor de Neu, carrer de la \\
\hline & Can Dragó, carrer de \\
\hline & Arítjols, carrer dels \\
\hline & Nou Pins, carrer de \\
\hline & Font de Canyelles, carrer de la \\
\hline & Molí, carrer del \\
\hline & Pou, carrer del \\
\hline & Canyameres, carrer de \\
\hline & Turó Blau, carrer del \\
\hline
\end{tabular}

\begin{tabular}{|c|c|}
\hline CATEGORÍA & NOMBRE DE LACAШE \\
\hline \multirow{4}{*}{$\begin{array}{l}\text { Personajes } \\
\text { históricos no } \\
\text { vinculados } \\
\text { directamente }\end{array}$} & Baltasar Gracián, carrer de \\
\hline & Sant Francesc Xavier, carrer de \\
\hline & Poeta Masifern, carrer del \\
\hline & Pablo Iglesias, carrer de \\
\hline \multirow{8}{*}{$\begin{array}{l}\text { Otros territorios } \\
\text { no vinculados } \\
\text { directamente }\end{array}$} & Rio de Janeiro, avinguda de \\
\hline & Valldaura, passeig de \\
\hline & Florida, carrer de la \\
\hline & Formentera, carrer de \\
\hline & Vesuvi, carrer del \\
\hline & Palamós, carrer de \\
\hline & Ponts, carrer de \\
\hline & Japó, carrer del \\
\hline \multirow{5}{*}{ Otras toponimias } & $\begin{array}{l}\text { Meridiana, avinguda } \\
\text { (por la línea del meridiano) }\end{array}$ \\
\hline & $\begin{array}{l}\text { Dalt, ronda de } \\
\text { (también conocida como II ronda) }\end{array}$ \\
\hline & $\begin{array}{l}\text { Favència, via } \\
\text { (por el nombre romano de Barcelona) }\end{array}$ \\
\hline & $\begin{array}{l}\text { Júlia, via } \\
\text { (por el nombre romano de Barcelona) }\end{array}$ \\
\hline & $\begin{array}{l}\text { Artesania, carrer de l' } \\
\text { (en honor a los artesanos) }\end{array}$ \\
\hline
\end{tabular}




\section{3 CARACTERIZACIÓN SOCIO E CON Ó M I CA}

\section{CARACTERIZACIÓN S.E.}

Según la información del Departamento de Estadistica y Difusión de Datos del Ayuntamiento de Barcelona, Nou Barris tiene casi el $10 \%$ de la población total de la ciudad (171.290 personas)

Para el caso de La Prosperitat, vemos entre los tres barrios con los que limita (Porta, Verdúm y Trinitat Nova), es el barrio con mayor cantidad de habitantes (26.834).

- POB. MUJERES

PROSPERITAT

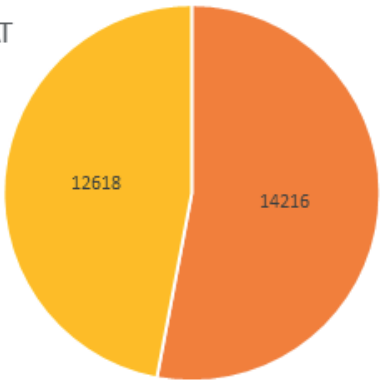

Fuente: Departamento de Estadísticas y Difusión de Datos del Ayuntamiento de Barcelona.

En: http:https://www.bcn.cat/estadistica/castella/index.htm
POBLACIÓN

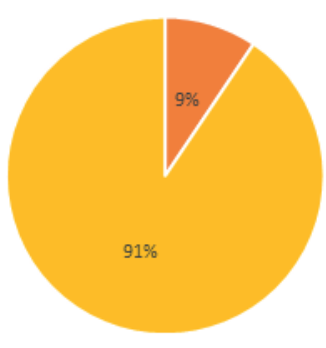

- Nou Barris |- Barcelona

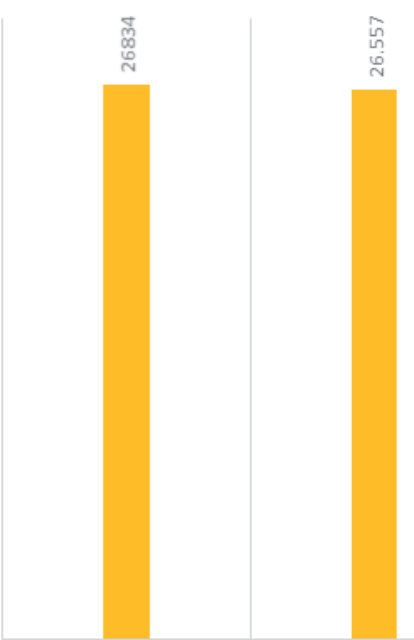

PROSPERITAT

\section{CARACTERIZACIÓN S.E.}

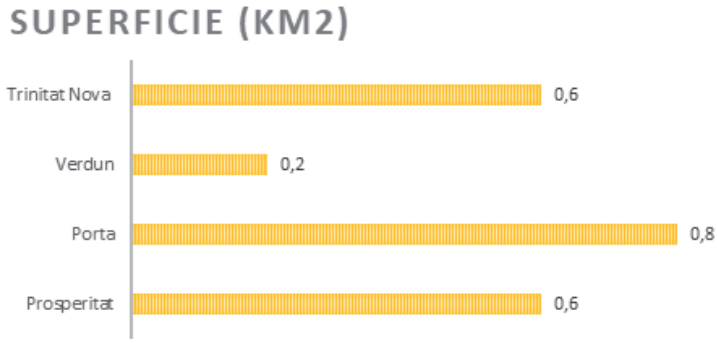

DENSIDAD (HAB/KM2)

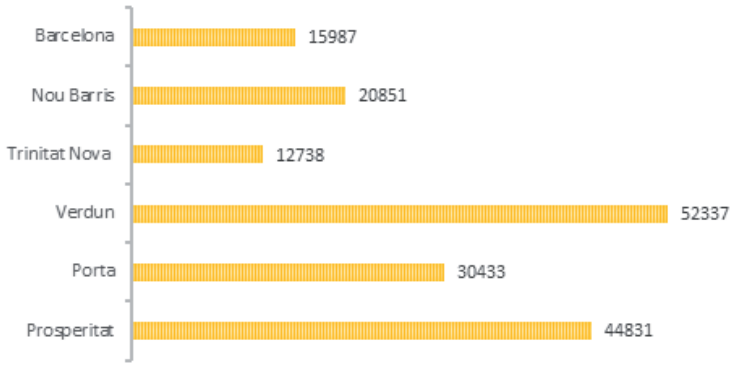

Al comparar la superficie de los territorios versus su densidad poblacional, vemos como no existe una real correlación. Por ejemplo, si bien Trinitat Nova y Prosperitat tienen la misma superficie $(0.6 \mathrm{~km} 2)$, Prosperitat tiene más del triple de densidad poblacional (cantidad de habitantes por kilómetro cuadrado).

Verdúm y Prosperitat están muy por encima del promedio de Barcelona y Nou Barris en cuanto densidad, ambos son barrios muy compactos.

\section{SUPERFICIE (KM2)}

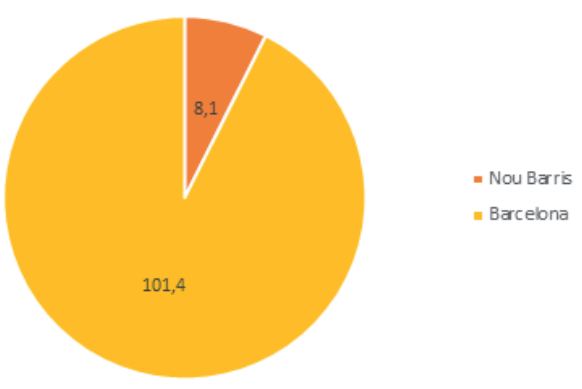

Fuente: Departamento de Estadísticas y Difusión de Datos del Ayuntamiento de Barcelona.

En :http:https://www.bcn.cat/estadistica/castella/index.htm 


\section{CARACTERIZACIÓN S.E.}

Respecto a la distribución etaria, podemos indicar que, si bien las tendencias son similares en todos los casos, La Prosperitat es el barrio que contiene mayor porcentaje de población mayor de 65 años (por sobre el promedio de Barcelona), y al mismo tiempo, el barrio que tiene menor porcentaje de habitantes en edad productiva (entre 25 y 64).

POB. 65 Y MÁS (\%)

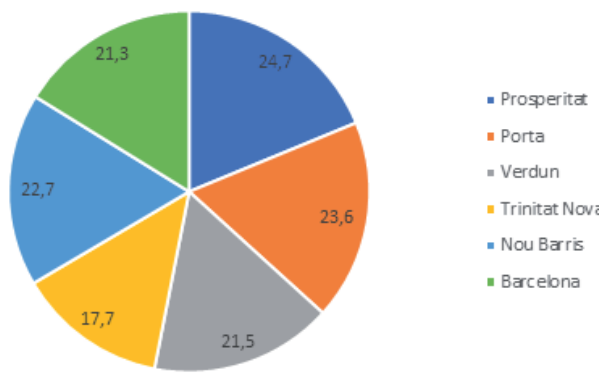

Fuente: Departamento de Estadísticas y Difusión de Datos del Ayuntamiento de Barcelona.

http:https://www.bcn.cat/estadistica/castella/index. htm

\section{CARACTERIZACIÓN S.E.}

Es interesante observar la conformación según origen en los distintos barrios. Tal como comentamos en la línea de tiempo, Prosperitat tiene una fuerte presencia de migrantes españoles no catalanes (25.9\%), más que el resto de los territorios comparados. Al mismo tiempo, es el barrio con menor porcentaje de población extranjera.

\section{ORIGEN DE LA POBLACIÓN}

- NAC. BARCELONA (\%)

NAC. RESTO CATALUNYA (\%)

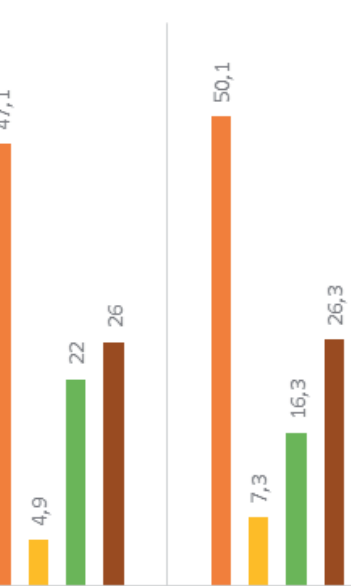

POB. ESPAÑOLA (\%)

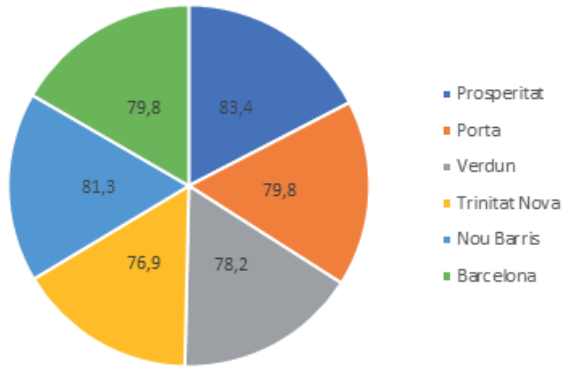

Fuente: Departamento de Estadísticas y Difusión de Datos del Ayuntamiento de Barcelona.

En:

http:https://www.bcn.cat/estadistica/castella/index. $\mathrm{htm}$ 


\section{CARACTERIZACIÓN S.E.}

TITULADOS SUPERIORES Y CFGS (\%)

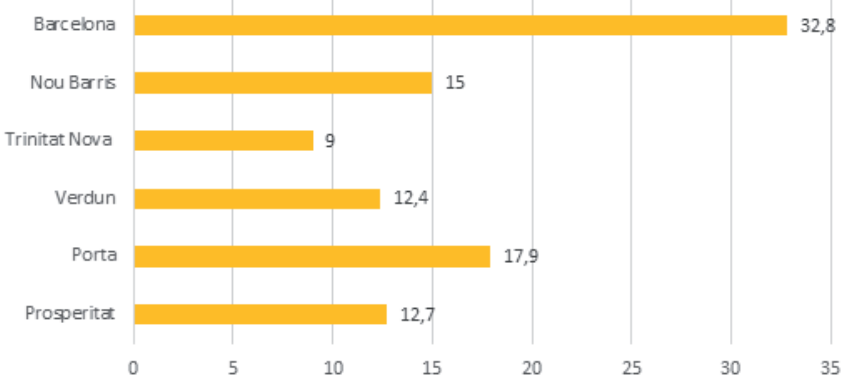

RENTA FAMILIAR DISPONIBLE POR HAB. (2017)

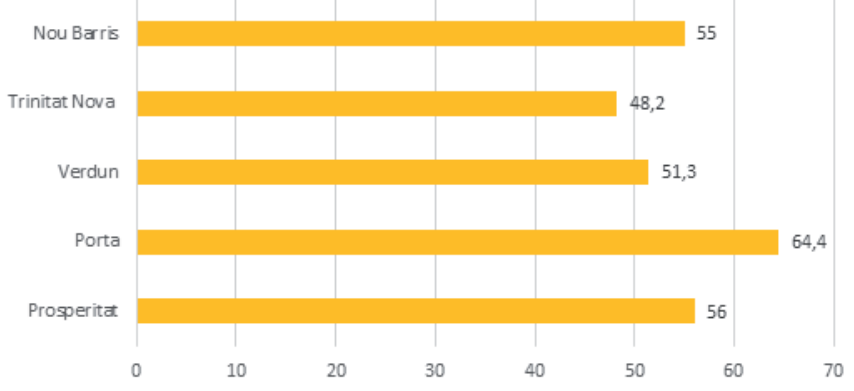

Por último, cabe resaltar que, si bien Prosperitat no cuenta con el porcentaje más bajo en escolaridad superior y CFGS, es el barrio que más número de parados tiene (1344) entre sus barrios limitrofes. Sin embargo, vemos que su RFD (dato 2017) es superior al promedio del distrito, solo superado por Porta.

\section{NÚM. DE PARADOS REGISTRADOS}

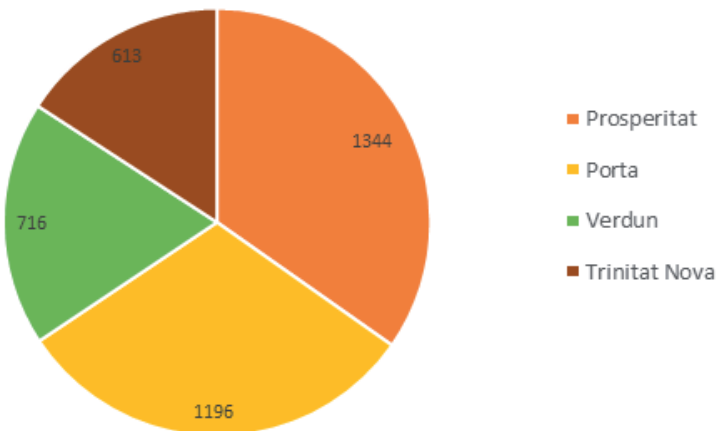

Fuente: Departamento de Estadísticas y Difusión de Datos del Ayuntamiento de Barcelona. En:

http:https://www.bcn.cat/estadistica/castella/index. htm

\section{CARACTERIZACIÓN S.E.}

Hemos visto que, a partir de los indicadores socio económicos del barrio, Prosperitat cumple con características de vulnerabilidad en diversos frentes. Tiene el mayor porcentaje de adultos mayores y el menor de población en edad productiva; una densidad poblacional muy alta para su superficie (más del triple que Trinitat Nova, por ejemplo.), y por último, el paro más cuantioso de los 4 barrios.

A pesar de estos indicadores, Prosperitat no cuenta con intervenciones de la Lley de Barris, tampoco de el $\mathrm{Pla}$ de Barris. Es un barrio que ha conseguido demandas utilizando un solo recurso, su propia lucha social.

Es interesante incorporar esta perspectiva, puesto que, en último término, la "planificación" de Prosperitat ha sido la propia comunidad, pujando implacablemente ante cada reivindicación. Podríamos decir que, a diferencia de un territorio diseñado desde arriba/fuera (22@ oVilla Olímpica, por ejemplo), Prosperitat simplemente no ha sido diseñado. Es el resultado de tensiones y conflictos, demandas ganadas y perdidas. Por un lado, esta característica pareciera otorgarle un aire más orgánico, traducido en asociatividad y cohesión.

\begin{tabular}{|l|}
\hline \multicolumn{1}{|c|}{$\begin{array}{c}\text { ASOCIACIONES EN } \\
\text { PROSPERITAT }\end{array}$} \\
\hline Cultura y científicas (7) \\
\hline Deportes (10) \\
\hline Economía (3) \\
\hline Educación (10) \\
\hline Humanidades y letras (10) \\
\hline Medio ambiente (1) \\
\hline Ocio (6) \\
\hline Partidos políticos (6) \\
\hline Sociedad (22) \\
\hline Técnica y tecnología (1) \\
\hline
\end{tabular}

\begin{tabular}{|l|l|}
\hline \multicolumn{1}{|l}{ LLEI DE BARRIS (2004-2009) } & PLA DE BARRIS (2016 Y-VIGENTE) \\
\hline Barcelona. Roquetes & $\begin{array}{l}\text { La Marina de Port i la Marina de Prat } \\
\text { Vermell }\end{array}$ \\
\hline Barcelona. Santa Caterina i Sant Pere & El Raval Sud i el Gòtic Sud \\
\hline Barcelona. Poble Sec & Sant Genís dels Agudells i la Teixonera \\
\hline Barcelona. Torre Baró-Ciutat Meridiana & Zona Nord (Torre Baró y Ciutat Meridiana) \\
\hline Barcelona. Trinitat Vella & Les Roquetes \\
\hline Barcelona. El Coll & La Trinitat Nova \\
\hline Barcelona. La Bordeta & La Trinitat Vella \\
\hline Barcelona. La Barceloneta & El Bon Pastor i Baró de Viver \\
\hline Barcelona. Maresme-Besòs & La Verneda i la Pau \\
\hline Baró de Viver- Bon pastor & El Besòs i el Maresme \\
\hline
\end{tabular}

Fuente Llei de Barris: Nel lo, Oriol, Director (2009). La Llei de barris. Una aposta col-lectiva per a la cohesió social. Generalitat de Catalunya.

Fuente Pla de Barris: El Pla de Barris de Barcelona 2016-2020 Memòria de seguiment, Març 2019, Ajuntament de Barcelona.

Fuente Asociaciones: Distrito de Nou Barris, Ayuntamiento de Barcelona.

En: https://ajuntament.barcelona.cat/noubarris/es/el-distrito-y-sus-barrios/la-prosperitat/ 


\section{CONECTIVIDAD}

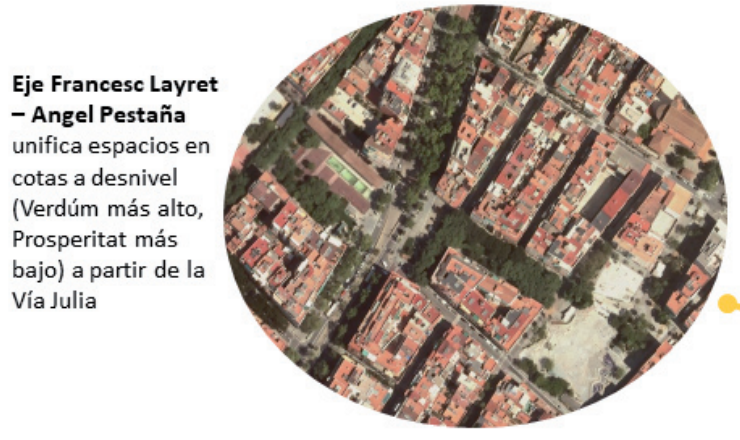

Plaza Uucmajor o de la República es un eje que articula Prosperitat, Verdúm, Guineueta y Porta $-=-1=$

Av. Río de Janeiro conecta Passeig Santa Colorna con P.
Vía Julia permite coser Verdúm y Prosperitat, además de ser el principal eje comercial

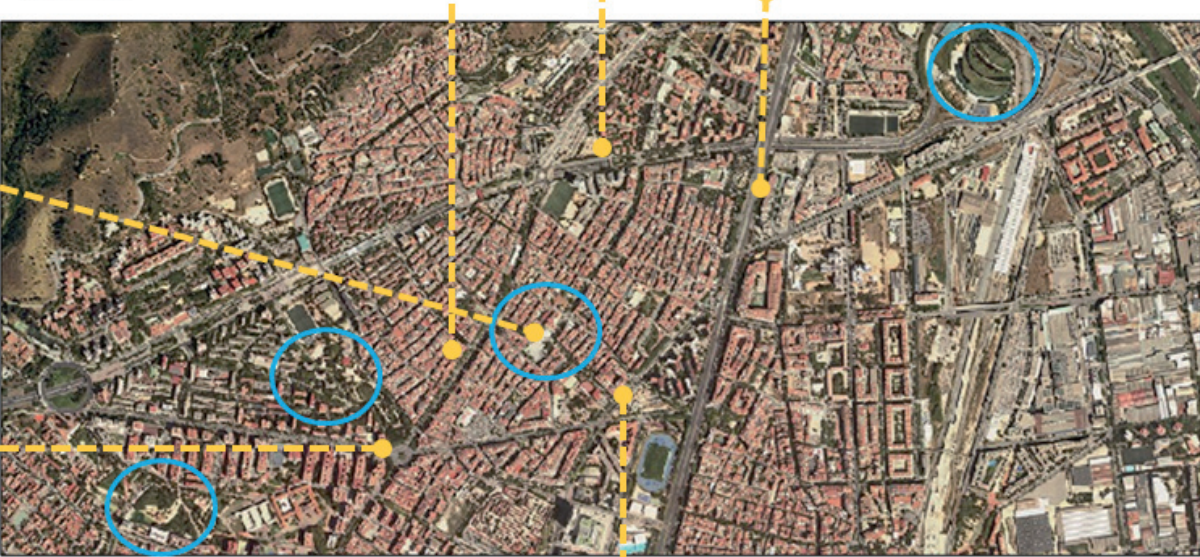

Encerrados en círculos celestes, podemos ver como se articulan espacios públicos (Parque de la Guinaueta, P. Central de Nou Barris, P. Trinitat Vella y al centro, el Eje Francesc Layret - Angel Pestaña.

\section{CONECTIVIDAD}

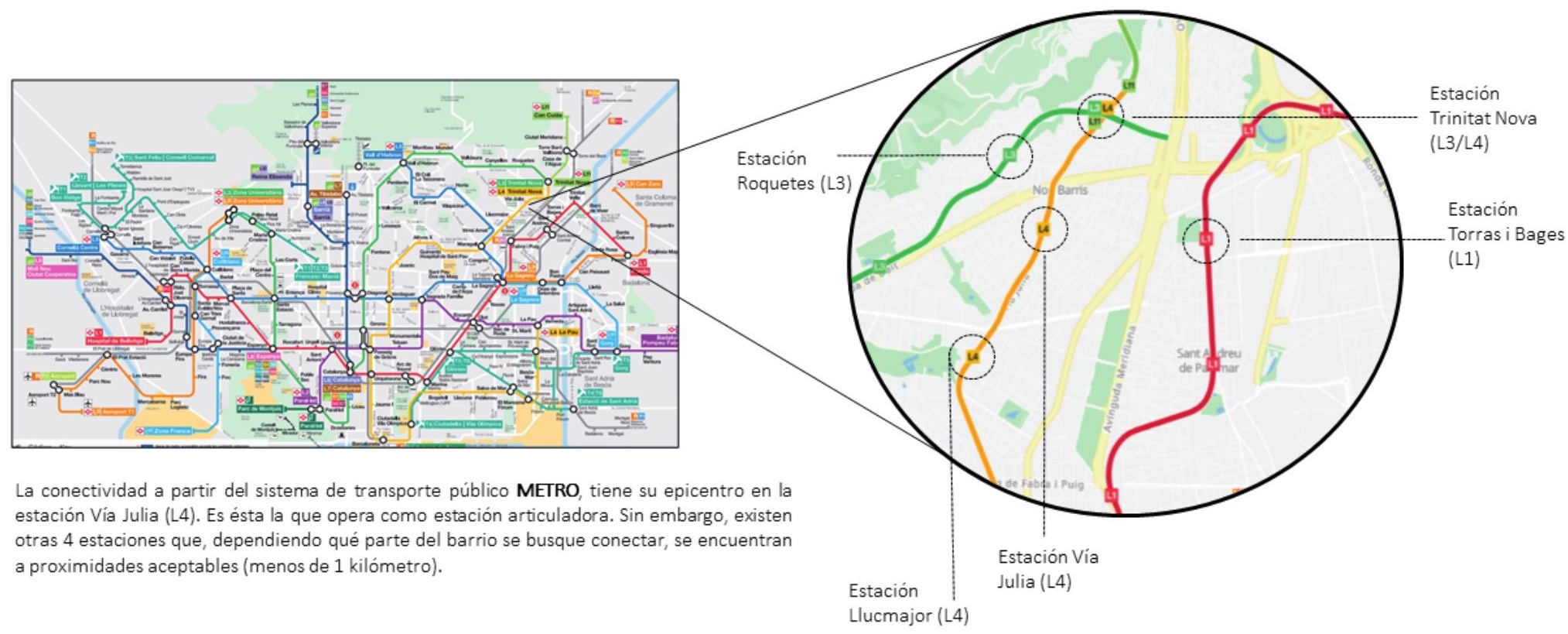

Fuente:TMB https://www.tmb.cat/es/transporte-barcelona/mapa/metro 


\section{CONECTIVIDAD}

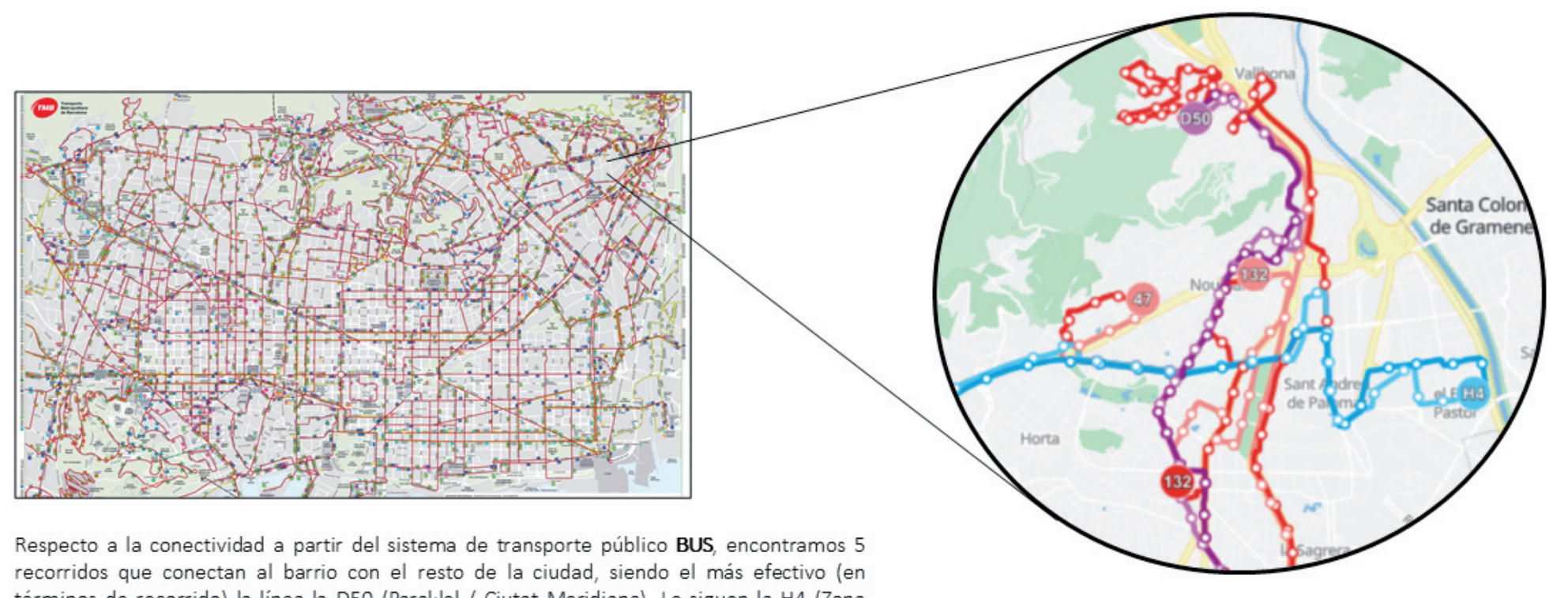

recorridos que conectan al barrio con el resto de la ciudad, siendo el más efectivo (en términos de recorrido) la línea la D50 (Paral-lel / Ciutat Meridiana). Le siguen la H4 (Zona Universitària / Bon Pastor), la 47 (Pg. Marítim / Canyelles), la 62 (Pl. Catalunya / Ciutat Meridiana) y la 132 (Torre Llobeta / Prosperitat).

Fuente:TMB https://www.tmb.cat/es/transporte-barcelona/mapa/me

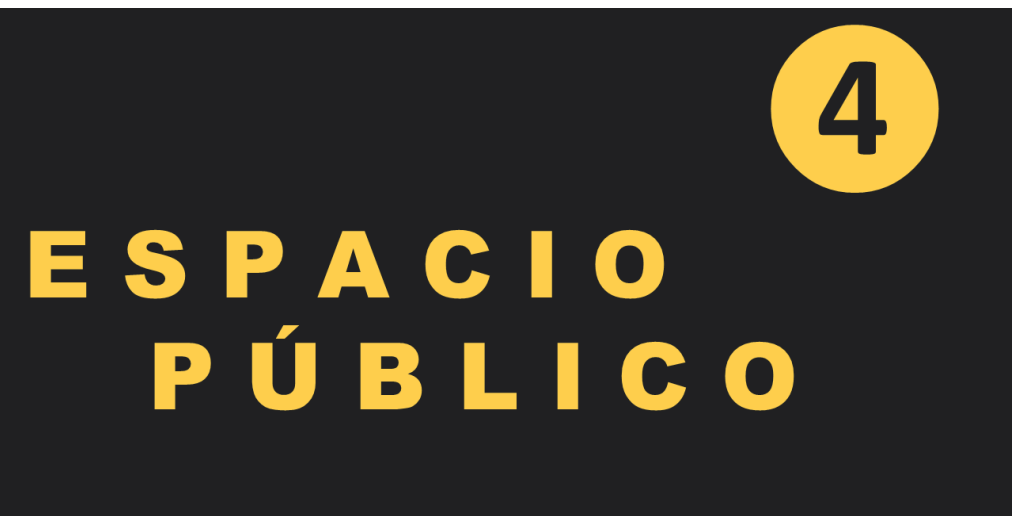

CARRER DE TISSO

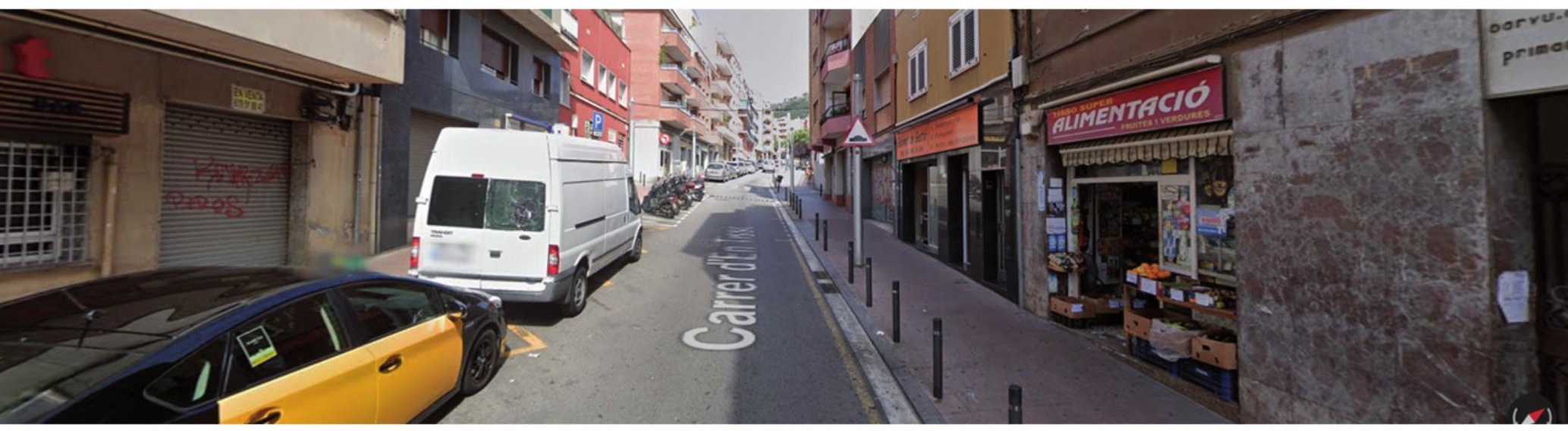

Antes de entrar en los puntos clave del espacio público del barrio, recorramos un poco las calles estrechas de La Prosperitat. Como indicamos al inicio, la proximidad y diversidad en la actividad de la planta baja son elementos relevantes a la hora de definir el modo de habitar un territorio. 


\section{ESPACIO PÚ BLICO}

CARRER DEL MOLÍ

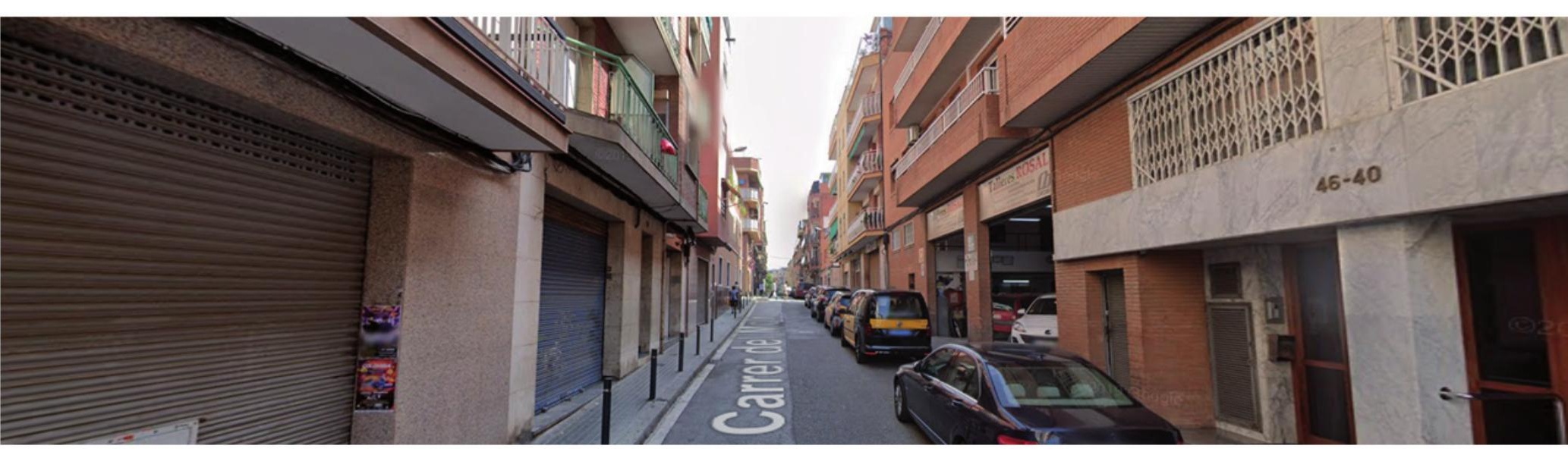

Si bien las calles son estrechas, vemos una importante utilización de ésta como aparcamiento.

Imagen tomada a partir de Google Street View (Julio, 2019)

\section{ESPACIO PÚ B LICO}

CARRER DE BADOSA

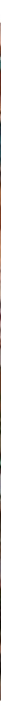

Predominan las fachadas típicas del desarrollismo (enchapado de ladrillo y el clásico toldo verde). Se mantiene un ritmo de fachada continua entre medianeras. Ciertamente ya casi no quedan casas (si es que aún existe alguna). 


\section{ESPACIO PÚBLICO}

CARRER DE PABLO IGLESIAS

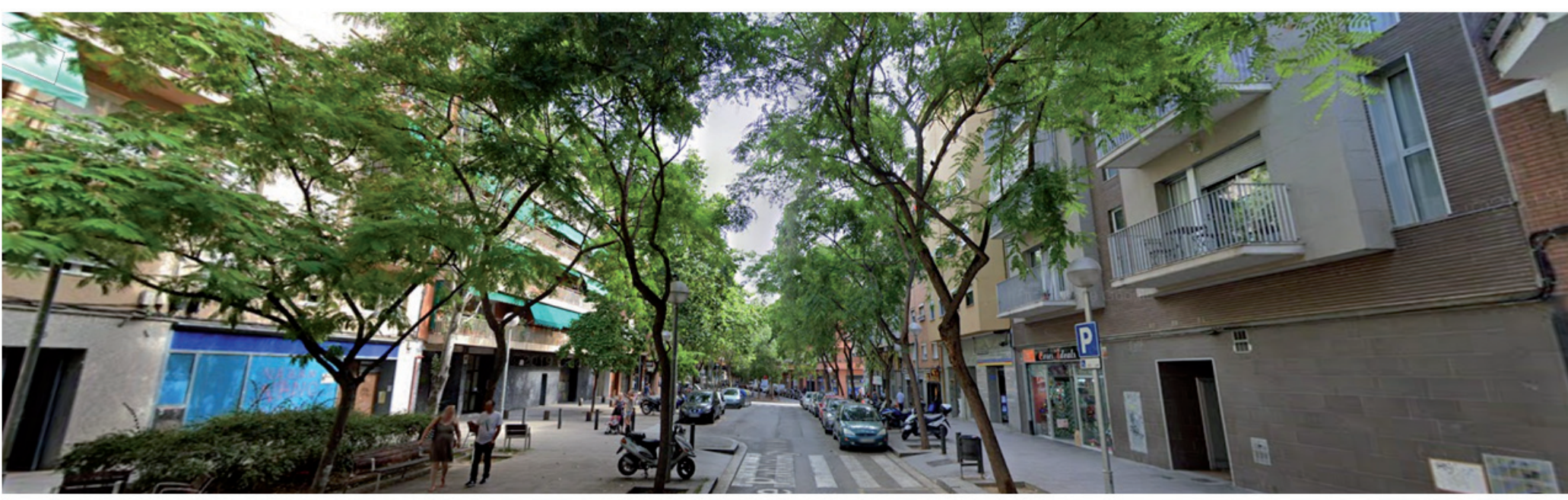

De las calles interiores del barrio, debe ser la principal. Amplias aceras y arbolado, junto a pequeños comercios. Es una especie de arteria central, un pasillo de aire a la densa trama del barrio.

Imagen tomada a partir de Google Street View (Julio, 2019)

\section{ESPACIO PÚBLICO}

CARRER DE ARTESANÍA

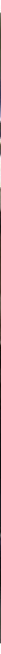

La bella Carrer de Artesanía, es un pequeño baipás (una versión diminuta de Av. Río de Janeiro) que une, cortando la esquina, a Paseo Valldaura con Vía Julia. 


\section{ESPACIO PÚBLICO}

El recorrido anterior da cuenta del ritmo urbano predominante en el barrio, sin embargo, existen 6 espacios públicos que otorgan al territorio particular notoriedad.

Estos puntos forman parte de lo que entenderemos como Red de Espacios Públicos, en tanto configuran un sistema de intervenciones realizadas, no solo en La Prosperitat, sino que en todo Nou Barris. En nuestro caso particular, presentaremos los siguientes:

1. Vía Julia

2. Plaza Llucmajor o de la República

3. Av. Río de Janeiro

4. Eje Francesc Layret-Angel Pestaña

5. Plaza Angel Pestaña

6. Plaza Harry Walker

Bajo las circunstancias actuales, y la imposibilidad de recorrer presencialmente el territorio nos valdremos del análisis realizado por Zuhra Sasa Marín (2012), quien presisamente estudia estos espacios, no solo desde una perspectiva arquitectónica, sino que desde su calidad en tanto espacio público para todos.

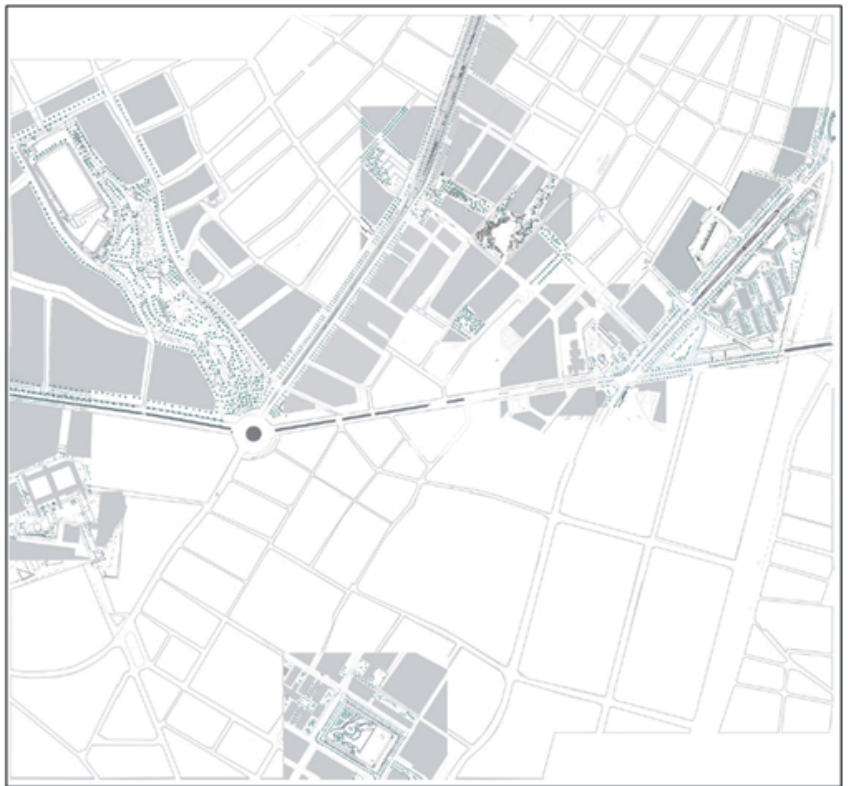

Red de Espacios Públicos, Fuente: Marín, Z. El modelo Barcelona de Espacio Público y Diseño UrbanO: CONSOUDACION URBANA DE NOU BARRIS A TRAVES DE LA RED DE ESPACIOS PUBLICOS, TFM Master Diseño Urbano, Universidad de Barcelona (2012).

\section{ESPACIO PÚBLICO}

1. VÍAJULIA

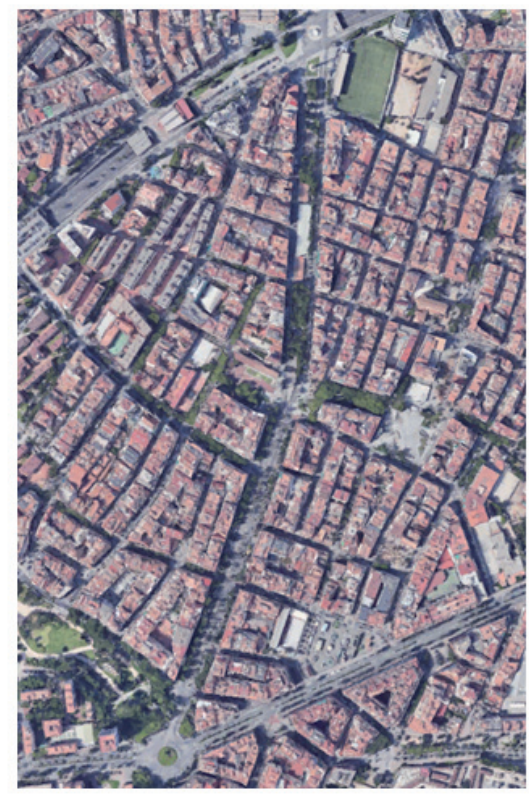

"La Vía Julia es el paradigma de diseño de espacio público de su época logrando dar orden a un espacio residual que carecía de elementos para asir una continuidad" (Marín, 2012)

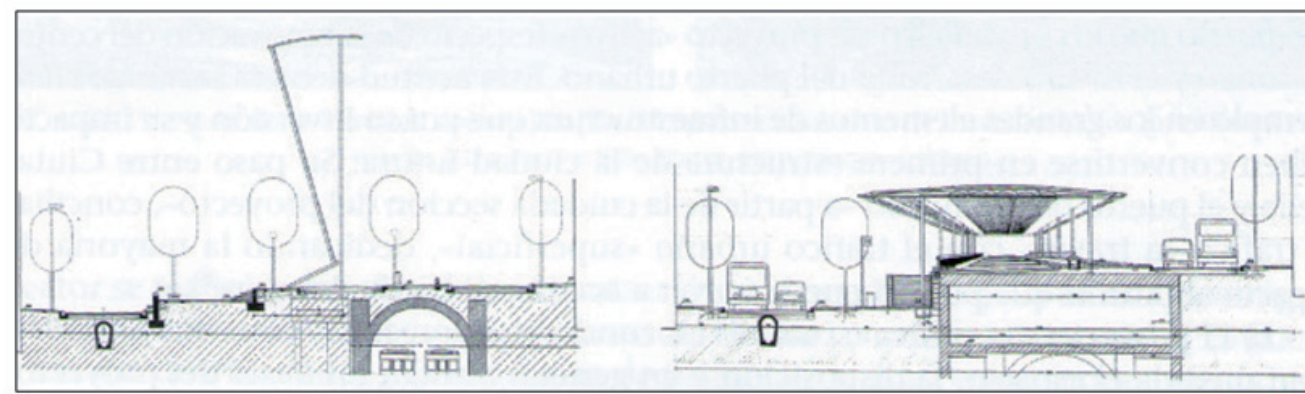

Vía originalmente planteada por León Jausely, pero que conllevaba una serie de dificultades urbanas que terminaban por incomunicar dos barrios hermanos (Prosperitat y Verdúm). El proyecto permitió dar solución a la diferencia de cotas que propiciaba dicho distanciamiento, dando paso a un paseo tipo rambla, marcado por importantes obras de arte público: al llegar a la Ronda de Dalt, con la Torre Favencia (Antoni Roselló, 1989), Als nous catalans (Sergi Aguilar, 1986) y al otro extremo con la simbólica reubicación de la estatua La República (Josep Viladomat, 1934)

Vía Julia, imagen en BUSQUETS, Joan. Barcelona. La construcción urbanística de una ciudad compacta. pág 377 Imagen Satelital deVía Julia, fuente: Google Earth:

https://earth.google.com/web/@41.44193924,2.17696039,95.32557952a, 1657.35540564d,35y, 14.24287017h,1.69 $810941 \mathrm{t}$,-Or 


\section{ESPACIO PÚBLICO}

1. VÍA JULIA

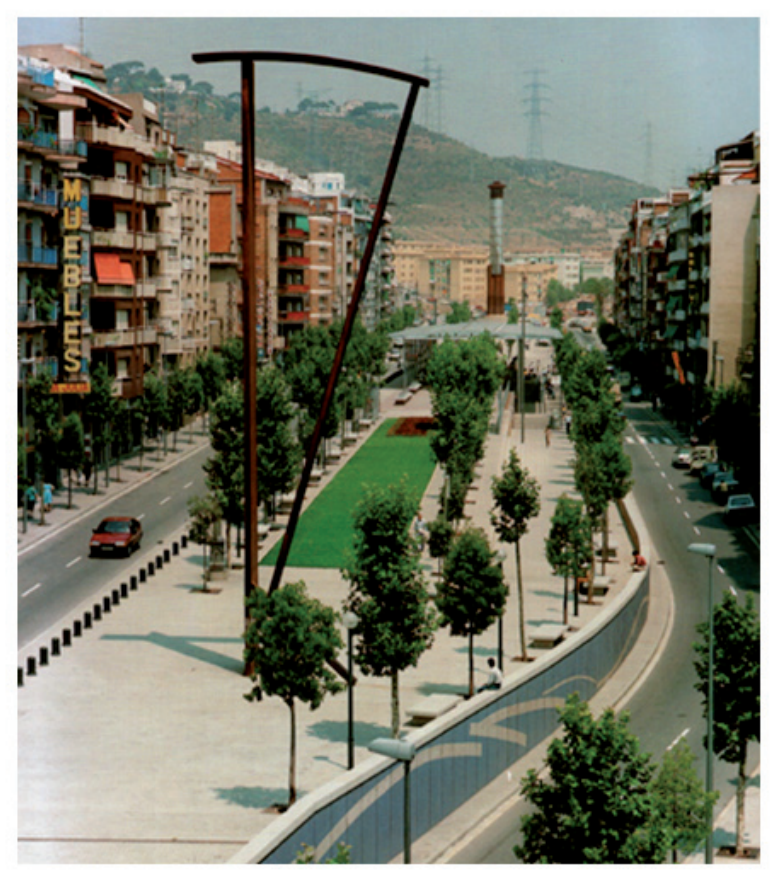

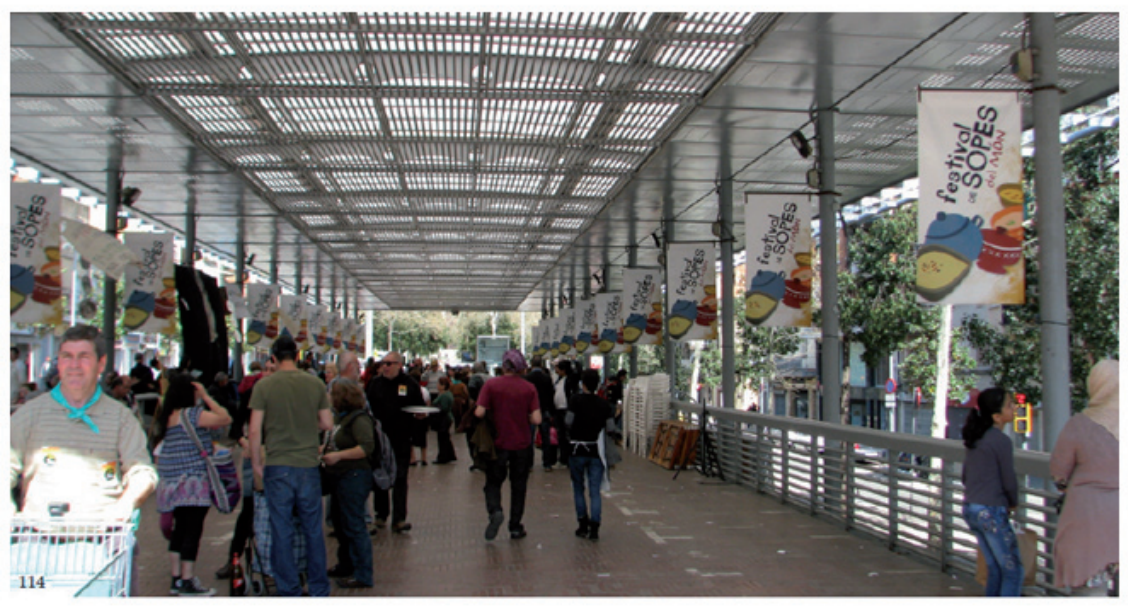

Imagen Vía Julia, fuente: Marín, Z. El modelo Barcelona de Espacio Público y Diseño Urbano: CONSOLIDACION URBANA DE NOU BARRIS A TRAVES DE LA RED DE ESPACIOS PUBLICOS, TFM Master Diseño Urbano, Universidad de Barcelona (2012)

Imagen Als Als nous catalans, fuente: Catálogo de Arte Públcio.

$\mathrm{http}: / /$ w10.bcn.cat/APPS/gmocataleg_monum/CambialdiomaAc.do?idioma=ca\&pagina=welcome

\section{ESPACIO PÚ BLICO}

\section{Plaza Llucmajor o de la República}

Además del simbolismo y épica propia de la historia de la escultura, el proyecto desarrollado por los arquitectos $\mathrm{H}$. Piñon y A. Vilaplana, termina por generar un verdadero hito urbano en la trama limitrofe de cuatro barrios vecinos (Prosperitat, Porta, Guineueta y Verdúm).

Según Marín (2012), la amplitud generada por el proyecto permite la activación del espacio aledaño, pero sobre todo termina por dotar de sentido a un territorio muy asociado con la censura y persecución.

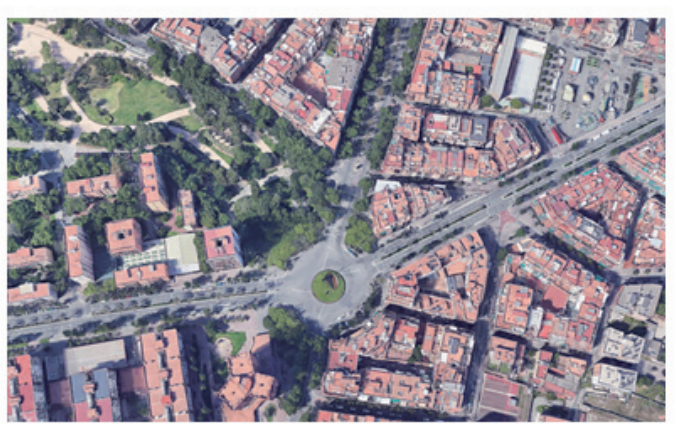

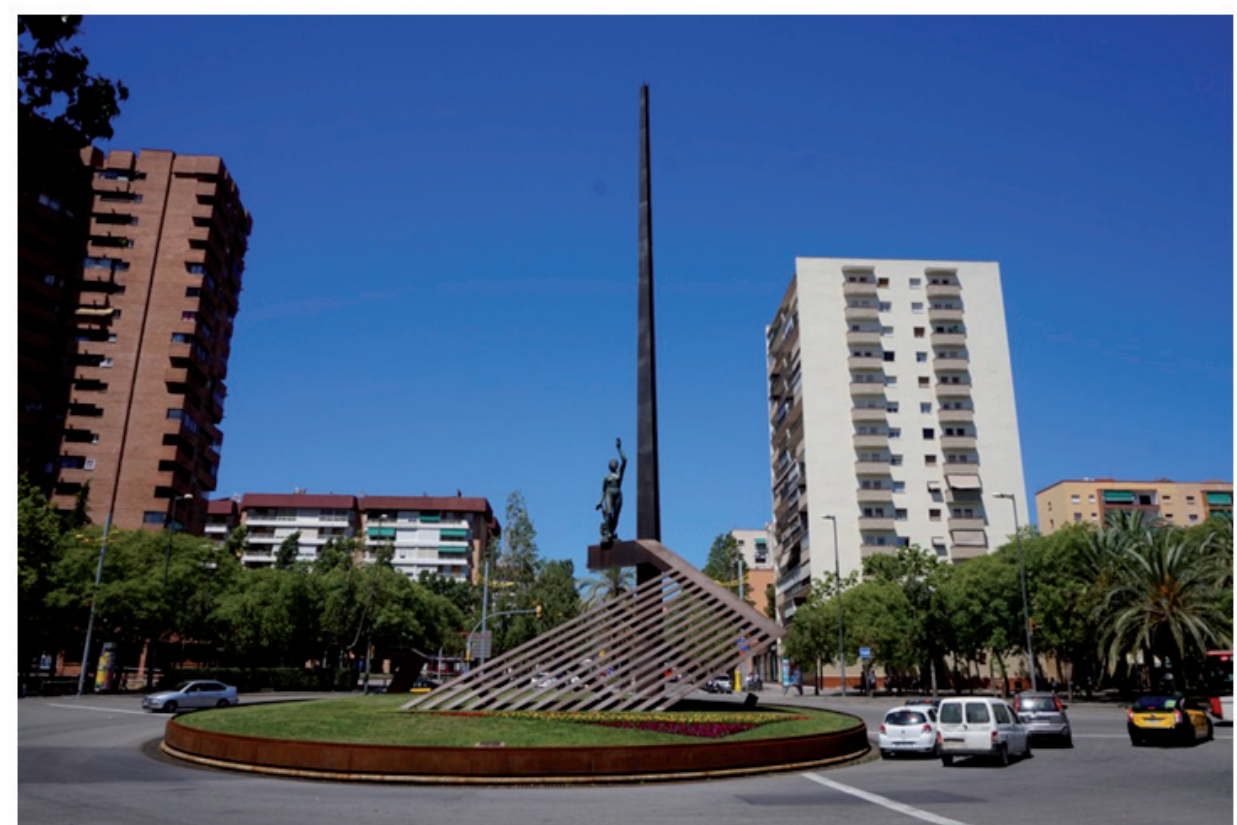

Imagen de la escultura recuperada, fuente: https://www.barcelona.cat/internationalwelcome/es/noticia/nou-barrisya-goza-oficialmente-de-plaza-de-la-republica 384665

Fuente imagen satelital: Google Earth: https://earth.google.com/web 


\section{ESPACIO PÚBLICO}

\section{Avenida Río de Janeiro}

Proyecto desarrollado por el Servicio de Proyectos y Elementos Urbanos del Ayuntamiento de Barcelona (P. Bardaji, C. Teixidor y A. Roquè).

Buscó hacerse cargo de una gran cicatriz creada por el trazado de la primera ronda (finalmente desechado). Del mismo modo que en Vía Julia, había que solucionar un problema diferencia de cotas, lo cual fue resuelto a partir de una serie de esculturas informales del artista Agusti Roque, las cuales forman parte de las pasarelas que sortean el desnivel. Esta intervención obtuvo premio FAD en 1989.

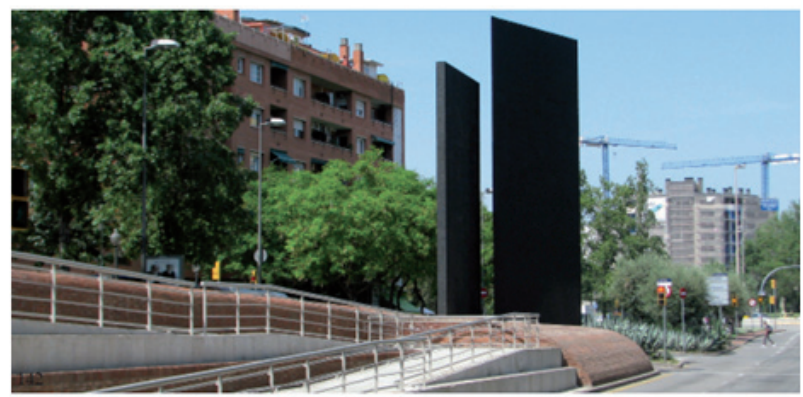

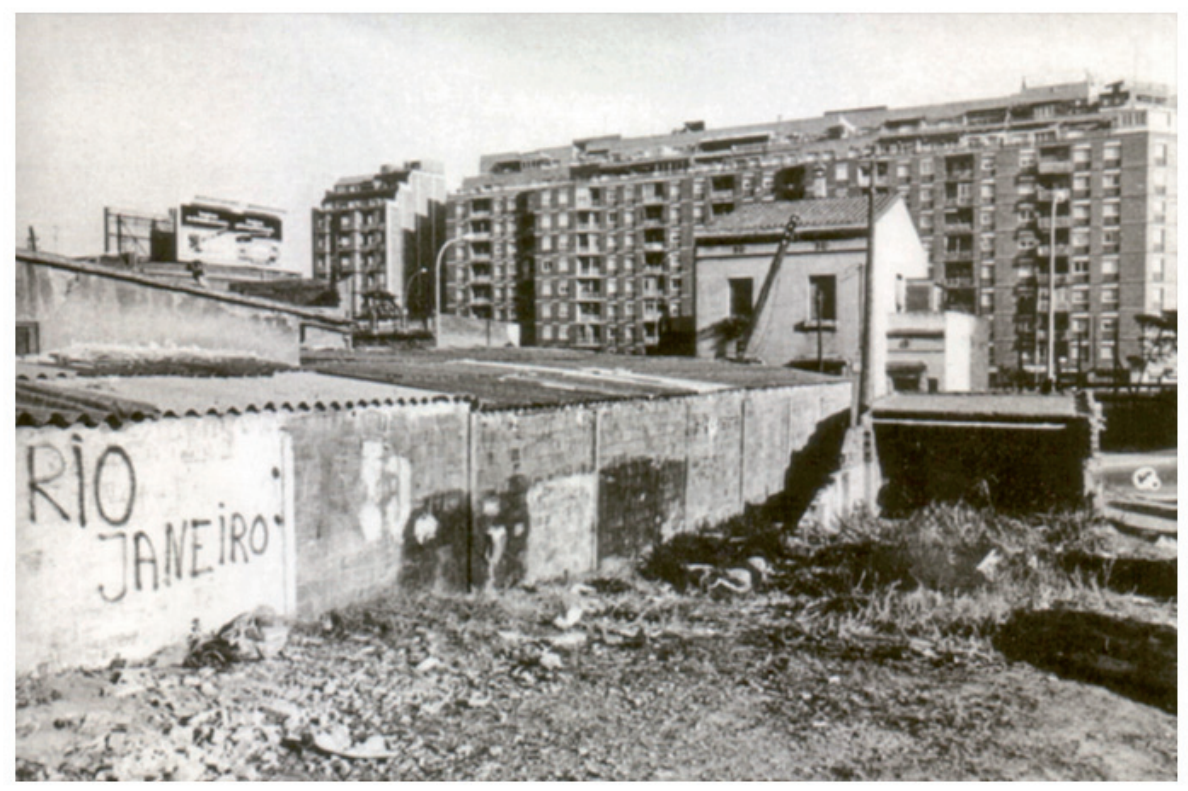

magen Av. Río de Janeiro. Fuente: Marín Z. El modelo Barcelona de Espacio Público y Diseño Urbano:

CONSOLIDACION URBANA DE NOU BARRIS A TRAVES DE LA RED DE ESPACIOS PUBLICOS, TFM Master Diseño Urbano, Universidad de Barcelona (2012)

Fuente Imagen antigua: https://laprosperitat100anvs.files.wordpress.com/2019/04/la-prosperitat-1919-2019.pdf

\section{ESPACIO PÚ BLICO}

\section{Eje Francesc Layret-Angel Pestaña}

La plaza Francesc Layret nace como consecuencia de la construcción de un parking subterráneo además de la necesidad de generar un eje transversal a la vía Julia. La remodelación se plantea en el 91, dando pie al enlace con la plaza de Ange Pestanya en Prosperitat a través de un eje peatonal ajardinado y con esculturas de Jaume Plensa y Enric Pladevall.

Este eje permite conectar dos espacios públicos importantes de los barrios de Prosperitaty Verdúm.

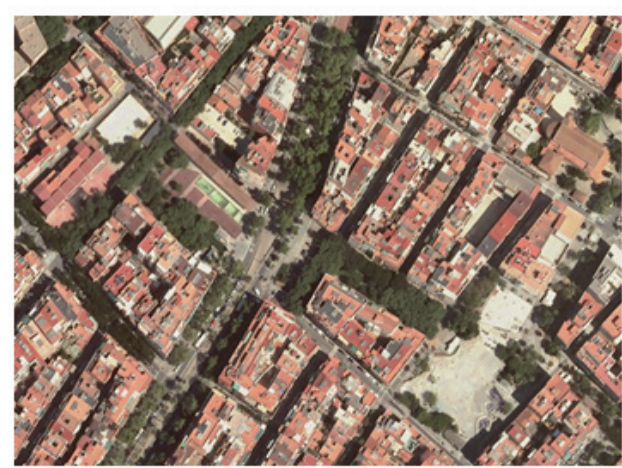

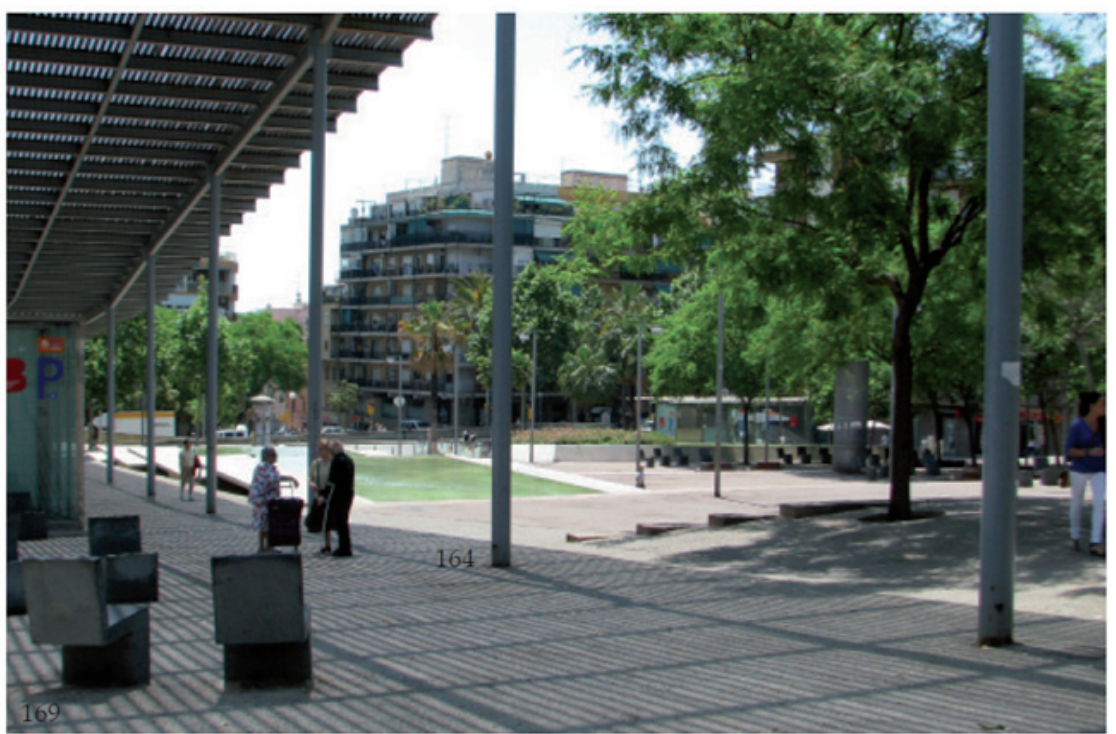

Imagen: Marín, Z. El modelo Barcelona de Espacio Público y Diseño Urbano: CONSOLIDACION URBANA DE NOU BARRIS A TRAVES DE LA RED DE ESPACIOS PUBLICOS, TFM Master Diseño Urbano, Universidad de Barcelona (2012) Fuente ortofoto: https://betaportal.icgc.cat/canurb/ 


\section{ESPACIO PÚBLICO}

\section{Plaza Angel Pestaña}

Espacio que nace como hecho reivindicativo de los vecinos (1984), quienes demandaban espacio 'público para un barrio que prácticamente no tenía. En el emplazamiento se encontraban las barracas de Santa Engracia, las cuales surgen producto de una estafa inmobiliaria la cual terminó por abandonar un solar del barrio y propiciar la ocupación de este.

Inaugurada en 1986, aunque posteriormente remodelada, es el verdadero espacio neurálgico del barrio. Aqui se realizan todas las actividades del barrio, desde la Fiesta Major hasta la famosa Prospe Beach.

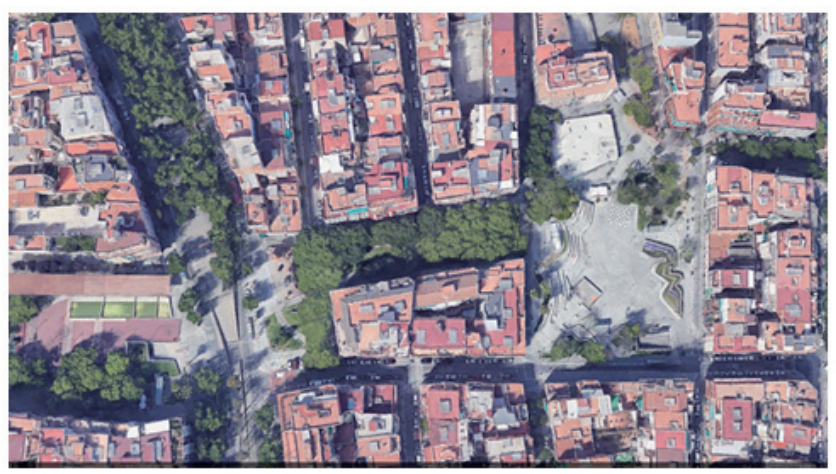

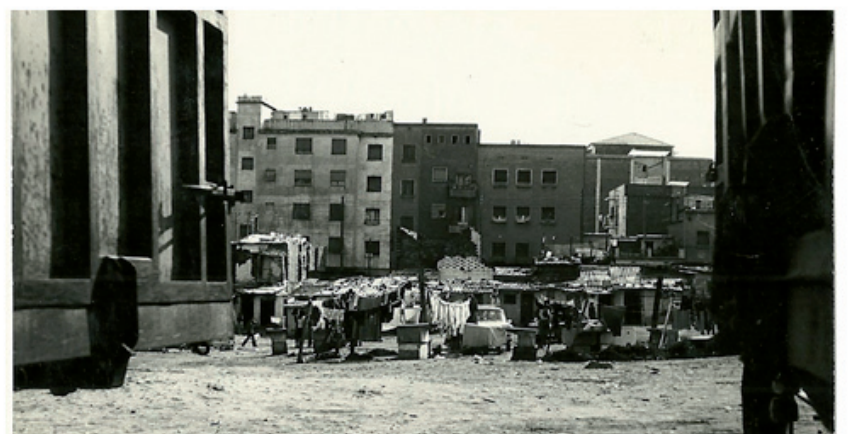

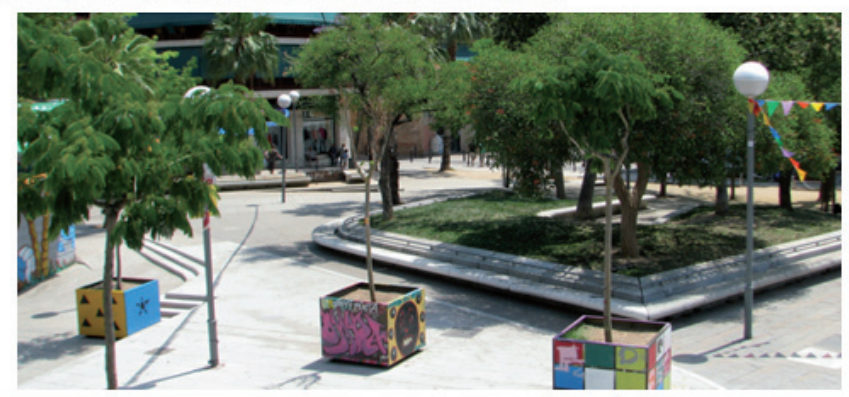

Imagen actual de la plaza. Fuente: Marín, Z. El modelo Barcelona de Espacio Público y Diseño Urbano:

CONSOLIDACION URBANA DE NOU BARRIS A TRAVES DE LA RED DE ESPACIOS PUBLICOS, TFM Master Diseño Urbano, Universidad de Barcelona (2012).

Fuente de las barracas. Fuente: http://memoriabcn.cat/noubarris/index/5/cast

Fuente imagen satelital: Google Earth: https://earth.google.com/web

\section{ESPACIO PÚBLICO}

\section{Plaza Harry Walker}

La principal relevancia de este espacio es simbólica. La huelga que terminó por poner en retirada a la fabrica que da nombre a la plaza, dio paso a manifestaciones por su recuperación como espacio público. Demanda que vería luz en el año 1999. Sobresale la fuente diseñada por Màrius Quintana.

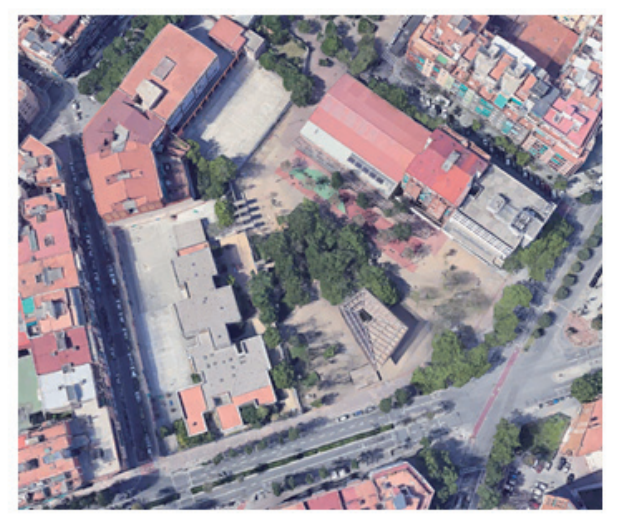

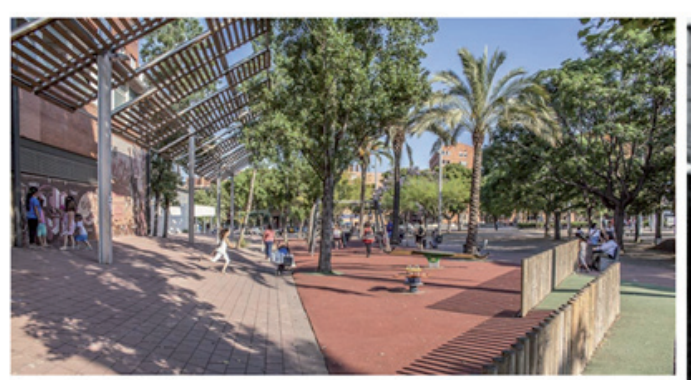

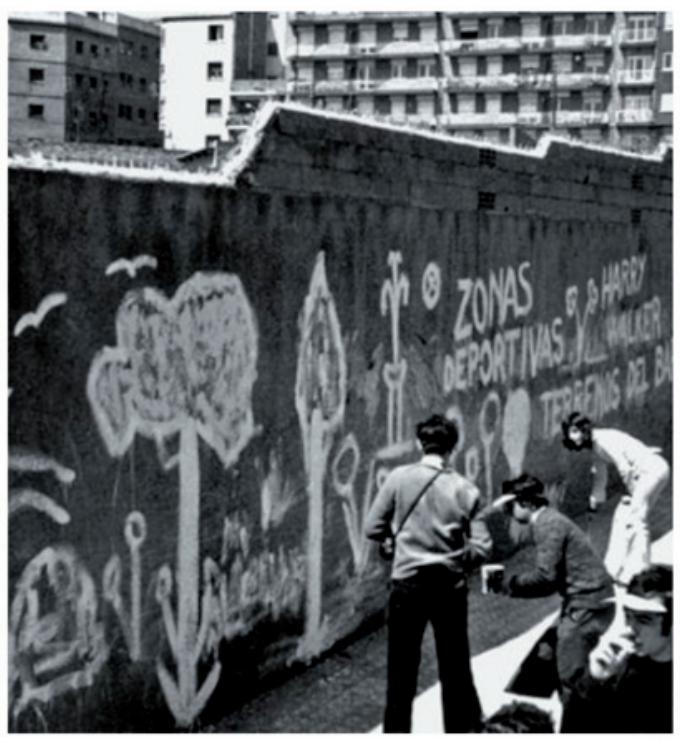

Imágenes actuales de la plaza. Fuente: https://ajuntament.barcelona.cat/noubarris/es/el-distrito-y-sus-barrios/el-distrito-y-susbarrios/la-prosperitat/la-prosperitat-memoria-historica

Imagen antigua de la plaza. Fuente: https://ajuntament.barcelona.cat/noubarris/es/noticia/el-ayuntamiento-edita-un-librosobre-la-harry-walker-en-el-centenario-de-la-prosperitat 793291 Fuente imagen satelital: Google Earth: https://earth.google.com/web 


\section{REFERENCIAS}

ABEYA, M.; SANCHEZ, J.; OYÓN, J. (2020). Conferencia "Cent anys de la Prosperitat: Taller de memòria històrica ». Disponible en: https://youtu.be/K4oYZyOzc4s

AJUNTAMENTDE BARCELONA. (2019) El Pla de Barris de Barcelona 2016-2020 Memòriade seguiment, Març2019.

BUSQUETS, JOAN. (2004). Barcelona. La construcción urbanística de una ciudad compacta, Serbal, España.

CANTALLOPS I VALERI, MONTERO MADARIAGA, DE SOLÀ-MORALES I RUBIÓ, DE TORRES I CAPELL, ROS HOMBRAVELLA, ESTEBAN I NOGUERA, RIBAS I PIERA, FONT ARELLANO. (1972) “EI Área Metropolitana de Barcelona". Cuadernos de Arquitectura y Urbansmo, $N^{\circ} 87$.

COMISSIÓ DEL CENTENARIDE LA PROSPERITAT. (2019). “100 anys de La Prosperitat, documentación 1919-2019”. Disponible en: https://www.yumpu.com/es/document/read/60209824/documentacio-100-prosperitat-maig-18/54

FERNÁNDEZ VALENTÍ, R. (2010). Destinació: Nou Barris, Un viatger per la historia dels transport sa Nou Barris. Ajuntamentde Barcelona, Districte de Nou Barris

NEL LO, ORIOL, (Director) (2009). La Llei de barris. Una aposta col/lectiva per a la cohesió social. Generalitat de Catalunya

SASA MARÍN, ZUHRA (2013) El modelo Barcelona de Espacio Público y Diseño Urbano: Consolidación urbana de Nou barris a través de la red de espacios públicos http://hdl.handle.net/2445/33303

TATJER, MERCÈ. 1997. «Los orígenes de la vivienda social en Barcelona: Las cooperativas de viviendas en el primer tercio del siglo XX». Coloquio sobre "El desarrollo urbano de Montréal y Barcelona en la época contemporánea: estudio comparativo»Universidad de Barcelona, 5-7 de mayo de 1997. http://www.ub.edu/geocrit/tatjben.htm.

TARRAGÓ, S. (1972) “GATEPAC I, El Pla Macia o La Nova Barcelona”. Cuadernos de Arquitectura y Urbanismo, º90. 